\title{
Perfluoropolyethers: Development of an All-Atom Force Field for Molecular Simulations and Validation with New Experimental Vapor Pressures and Liquid Densities
}

\author{
Jana E. Black, ${ }^{\dagger, \ddagger \odot}$ Gonçalo M. C. Silva, ${ }^{\S}$ Christoph Klein, ${ }^{\dagger \dagger}$ Christopher R. Iacovella, ${ }^{\dagger, \ddagger}$ Pedro Morgado, ${ }^{\S}$ \\ Luís F. G. Martins, ${ }^{\S, \|}$ Eduardo J. M. Filipe, ${ }^{\S \odot}$ and Clare McCabe ${ }^{*, \dagger, \ddagger, \perp}$ \\ ${ }^{\dagger}$ Department of Chemical and Biomolecular Engineering, Vanderbilt University, Nashville, Tennessee 37235, United States \\ ${ }^{\ddagger}$ Multiscale Modeling and Simulation (MuMS), Vanderbilt University, Nashville, Tennessee 37235, United States \\ ${ }^{\S}$ Centro de Química Estrutural, Instituto Superior Técnico, Universidade de Lisboa, 1049-001 Lisboa, Portugal \\ "Centro de Química de Évora, Universidade de Évora, Rua Romão Ramalho, 59, 7000-671 Évora, Portugal \\ ${ }^{\perp}$ Department of Chemistry, Vanderbilt University, Nashville, Tennessee 37235, United States
}

Supporting Information

ABSTRACT: A force field for perfluoropolyethers (PFPEs) based on the general optimized potentials for liquid simulations all-atom (OPLS-AA) force field has been derived in conjunction with experiments and ab initio quantum mechanical calculations. Vapor pressures and densities of two liquid PFPEs, perfluorodiglyme $\left(\mathrm{CF}_{3}-\mathrm{O}-\left(\mathrm{CF}_{2}-\mathrm{CF}_{2}-\mathrm{O}\right)_{2}-\mathrm{CF}_{3}\right)$ and perfluorotriglyme $\left(\mathrm{CF}_{3}-\mathrm{O}-\left(\mathrm{CF}_{2}-\mathrm{CF}_{2}-\mathrm{O}\right)_{3}-\mathrm{CF}_{3}\right)$, have been measured experimentally to validate the force field and increase our understanding of the physical properties of PFPEs. Force field parameters build upon those for related molecules (e.g., ethers and perfluoroalkanes) in the OPLS-AA force field, with new parameters introduced for interactions specific to PFPEs. Molecular dynamics simulations using the new force field demonstrate excellent agreement with $a b$ initio calculations at the RHF/6-31G* level for gas-phase torsional energies $\left(<0.5 \mathrm{kcal} \mathrm{mol}^{-1}\right.$ error) and molecular structures for several

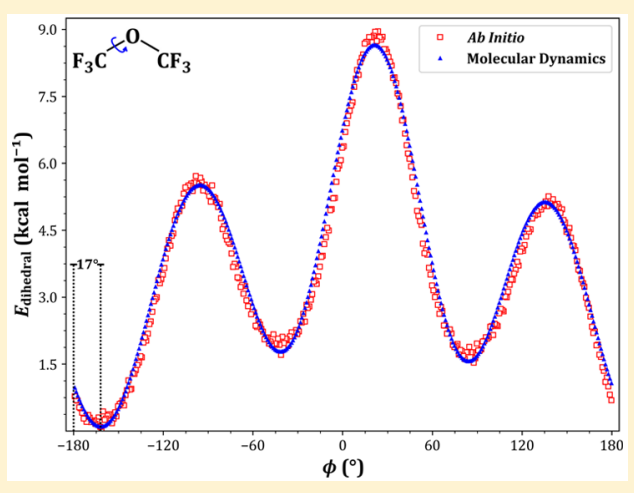
PFPEs, and also accurately reproduce experimentally determined densities $\left(<0.02 \mathrm{~g} \mathrm{~cm}^{-3}\right.$ error $)$ and enthalpies of vaporization derived from experimental vapor pressures $\left(<0.3 \mathrm{kcal} \mathrm{mol}^{-1}\right)$. Additional comparisons between experiment and simulation show that polyethers demonstrate a significant decrease in enthalpy of vaporization upon fluorination unlike related molecules (e.g., alkanes and alcohols). Simulation suggests this phenomenon is a result of reduced cohesion in liquid PFPEs due to a reduction in localized associations between backbone oxygen atoms and neighboring molecules.

\section{INTRODUCTION}

Perfluoropolyethers (PFPEs) have attracted interest from several different fields because they possess a unique combination of advantageous physical and chemical properties. For example, they are chemically inert, nontoxic, and nonflammable, possess high thermal and oxidative stability, have a wide liquid temperature range, and have high viscosity indices. $^{1-4}$ In particular, these properties provide them with excellent lubricating behavior and as a result PFPEs are used in aerospace/aviation applications (e.g., aircraft instrument bearings and valves/O-rings for oxygen service in space suits and vehicles), ${ }^{1,5,6}$ in the nuclear industry, ${ }^{1,5,7}$ in automotive applications (e.g., inertial navigation system (INS) gyroscopes and antilock braking system (ABS) pistons and bearings), ${ }^{1,6-8}$ and in food and pharmaceutical processes (e.g., product manufacturing and processing). ${ }^{7,9,10}$ PFPEs are also widely used in electronics manufacturing, where they are considered the best class of lubricants for clean room and high vacuum applications (e.g., semiconductor device fabrication) because they have low volatility and outgassing and are nonflammable and inert toward the reactive chemicals involved in such applications. ${ }^{1,7,11}$ Furthermore, PFPEs are suitable for electronic devices operating at high temperatures because they can withstand constant temperatures as high as $500 \mathrm{~K}$ and intermittent temperatures up to $700 \mathrm{~K}$ or higher. ${ }^{1,7}$ For example, functionalized PFPEs such as Fomblin $\mathrm{Z}$ derivatives $\left(\mathrm{X}-\mathrm{CF}_{2}-\mathrm{O}-\left(\mathrm{CF}_{2}-\mathrm{CF}_{2}-\mathrm{O}\right)_{m}-\left(\mathrm{CF}_{2}-\mathrm{O}\right)_{n}-\mathrm{CF}_{2}-\mathrm{X}\right)$ are used to lubricate the surfaces of hard disk drives because they are able to withstand the high shear rates and temperatures associated with hard disk drive operation. ${ }^{1,12}$ Hard disk drives belong to a class of devices called nanoelectromechanical systems (NEMS), which have small lateral dimensions and therefore large surface-area-to-volume ratios, which, without lubrication, can result in significant surface interactions, e.g.,

Received: January 27, 2017

Revised: May 27, 2017

Published: May 30, 2017 
adhesion and friction, that can lead to surface damage and eventual device failure. ${ }^{13,14}$ PFPE-based lubrication schemes show great promise for wider application in NEMS devices, as evidenced by the ability of functionalized PFPE thin-films to effectively protect and lubricate contacting surfaces in hard disk drives. $^{1,12}$

Given the wide range of applications for PFPEs, it would be of great value to be able to accurately model PFPE-based lubrication schemes with molecular simulation in order to improve our understanding of their atomic-level behavior. To date, most theoretical studies involving PFPEs have used coarse-grained (CG) force fields in an attempt to reduce computational cost (see, e.g., refs 15-20). The most widely used force field is based on a CG bead-spring model for functionalized PFPEs that was originally developed by Guo et al.; ${ }^{15}$ functionalized PFPEs (e.g., derivatives of Fomblin $\mathrm{Z}^{12}$ and Demnum $^{21}$ ) are modeled using only two types of pseudoatoms, or beads: "backbone" beads to represent repeat units and "end" beads to represent functional end groups. ${ }^{15,16}$ Note that these models do not distinguish differences in repeat units (e.g., $\left(\mathrm{CF}_{2}-\mathrm{CF}_{2}-\mathrm{O}\right)_{m}-\left(\mathrm{CF}_{2}-\mathrm{O}\right)_{n}$ in Fomblin $\mathrm{Z}$ and $\left(\mathrm{CF}_{2}-\mathrm{CF}_{2}-\right.$ $\mathrm{O})_{m}$ in Demnum) and rarely distinguish differences in functional end groups; for example, Chen et al. used one type of end bead to represent the functional end groups of Fomblin $\mathrm{Zdol}\left(-\mathrm{CH}_{2} \mathrm{OH}\right)$ and DDPA-S ( $-\mathrm{N}$ $\left.\left(\mathrm{CH}_{2} \mathrm{CH}_{2} \mathrm{CH}_{3}\right)_{2}\right){ }^{16}$ Furthermore, these force fields were parametrized without any connection to experiments or allatom (AA) calculations and severely simplify the PFPE molecular structure; the simulation results are therefore mostly qualitative in nature. More complex CG models of PFPEs, which were derived from AA simulations using the universal force field (UFF) ${ }^{17,18}$ and condensed-phase optimized molecular potentials for atomistic simulation studies (COMPASS $)^{19,20}$ force field, have been independently developed. These models accurately reproduce molecular structures predicted by their parent AA force fields, with the model derived from COMPASS also reproducing predicted liquid properties (e.g., viscosity ${ }^{19}$ and density ${ }^{19,20}$ ). However, it is unclear whether the parent AA force fields are suitable for PFPEs, as they have not been sufficiently tested against experimental data.

A much smaller number of theoretical studies have used AA force fields to study PFPEs. ${ }^{22-32}$ For example, Jiang et al. used the UFF to investigate the bulk rheological properties of perfluorotriglyme as a function of temperature and shear rate and predicted shear thinning behavior at all temperatures. ${ }^{22}$ Tani et al. studied the conformational behavior of various PFPE thin-films on hydrogenated carbon surfaces using the DREIDING force field and determined that molecular structure (i.e., backbone type and end group functionalization) could impact lubricant film thickness, ${ }^{23,24}$ surface coverage, ${ }^{24,25}$ and adhesive properties. ${ }^{26}$ However, these AA force fields were not derived to specifically model PFPEs and have not been sufficiently validated for use with PFPEs, which is of particular concern given that, unlike molecules containing related functional groups (e.g., hydrogenated ethers, perfluoroalkanes, and perfluoroalcohols), PFPEs tend to adopt asymmetric conformations about ether (i.e., C-O) bonds, ${ }^{33,34}$ which may significantly impact fundamental molecular properties. While Li et al. previously derived a united-atom (UA) potential specifically for PFPEs, ${ }^{2,3}$ to date, no such all-atom force field has been developed.
In this work, experiments, $a b$ initio quantum mechanical (QM) calculations, and molecular dynamics (MD) simulations have been combined to develop and validate an all-atom force field for PFPEs that is compatible with the current optimized potentials for liquid simulations all-atom (OPLS-AA) force field $^{35}$ and provide additional insight into the behavior of these systems. OPLS-AA has been shown to accurately reproduce experimental properties for molecules containing similar functional groups (e.g., hydrogenated ethers, ${ }^{35}$ perfluoroalkanes, $^{36,37}$ and perfluoroalcohols ${ }^{38,39}$ ), and thus serves as an ideal starting point for the development of a general force field for PFPEs. Experiments were performed to obtain the data required to parametrize, test, and refine the force field as well as increase our understanding of the thermodynamic properties of PFPEs. Vapor pressures $\left(P_{\text {vap }}\right)$ and liquid densities $(\rho)$ as a function of temperature were measured experimentally for two liquid PFPEs, perfluorodiglyme $\left(\mathrm{CF}_{3}-\mathrm{O}-\left(\mathrm{CF}_{2}-\mathrm{CF}_{2}-\mathrm{O}\right)_{2}-\right.$ $\left.\mathrm{CF}_{3}\right)$ (Figure 1A) and perfluorotriglyme $\left(\mathrm{CF}_{3}-\mathrm{O}-\left(\mathrm{CF}_{2}-\right.\right.$

A

$$
\mathrm{F}_{3} \mathrm{C}^{-\mathrm{O}} \backslash_{\mathrm{CF}_{2}}^{-\mathrm{CF}_{2}} \backslash_{\mathrm{O}^{-}}-\mathrm{CF}_{2} \mathrm{CF}_{2}-{ }^{-\mathrm{O}}{ }_{\mathrm{CF}_{3}}
$$

B

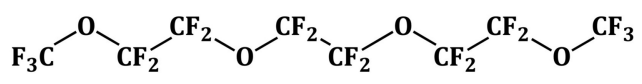

Figure 1. Structural formulas of $(\mathrm{A})$ perfluorodiglyme $\left(\mathrm{CF}_{3}-\mathrm{O}-\right.$ $\left.\left(\mathrm{CF}_{2}-\mathrm{CF}_{2}-\mathrm{O}\right)_{2}-\mathrm{CF}_{3}\right)$ and $(\mathrm{B})$ perfluorotriglyme $\left(\mathrm{CF}_{3}-\mathrm{O}-\left(\mathrm{CF}_{2}-\right.\right.$ $\left.\left.\mathrm{CF}_{2}-\mathrm{O}\right)_{3}-\mathrm{CF}_{3}\right)$.

$\left.\mathrm{CF}_{2}-\mathrm{O}\right)_{3}-\mathrm{CF}_{3}$ ) (Figure $1 \mathrm{~B}$ ); molar enthalpies of vaporization $\left(\Delta H_{\text {vap }}\right)$ were calculated from the experimental vapor pressures. Perfluorodiglyme and perfluorotriglyme are essentially smaller analogues of PFPEs that are used as high performance lubricants (e.g., Fomblin Z). To the best of our knowledge, experimental vapor pressures and densities of these substances have not been previously determined; this work is thus an initial effort to fill an important gap in the current literature regarding fundamental properties of PFPEs. QM calculations were also performed for perfluorodiglyme, perfluorotriglyme, and other small PFPEs to determine equilibrium bond lengths and angles from minimum energy molecular structures and torsional energy landscapes, which were used to fit force field parameters; additional QM calculations were performed to test the force field's ability to predict minimum energy molecular conformations of PFPEs. Following validation of the new force field, values of $\Delta H_{\text {vap }}$ predicted by $\mathrm{MD}$ simulations were compared to those from experiments of hydrogenated and fluorinated analogues of polyethers, alkanes, and alcohols.

\section{EXPERIMENTAL METHODS}

Materials. Perfluorodiglyme (perfluoro (diethylene glycol dimethyl ether), CAS 40891-99-4) and perfluorotriglyme (perfluoro (triethylene glycol dimethyl ether), CAS 64028-042) were purchased from Apollo Scientific Ltd.; 98\% purity was claimed for both liquids. The compounds were used as received, and the purity of the samples was confirmed by ${ }^{19} \mathrm{~F}$ NMR spectroscopy before and after the vapor pressure measurements.

Vapor Pressure Measurements. The vapor pressures of perfluorodiglyme and perfluorotriglyme were measured at temperatures ranging from 278-328 and 288-328 $\mathrm{K}$, 
respectively. The measurements were made using a static apparatus previously described ${ }^{40}$ in which a spherical glass cell is connected to a vacuum line and to a pressure transducer; the glass cell is kept under a thermostatic water bath. The temperature was measured using a calibrated Pt100 temperature sensor connected to a Keithley $200061 / 2$ digital multimeter, with an absolute uncertainty of $0.05 \mathrm{~K}$. The temperature stability and uniformity during a measurement are estimated to be better than $0.01 \mathrm{~K}$. The pressure was measured with a Paroscientific Series 1000 quartz absolute pressure transducer connected to a Paroscientific model 715 display unit. The pressure sensor used has an automatic temperature compensation system and a maximum measurement limit of $689 \mathrm{kPa}$, with a resolution of $0.0001 \%$ at the upper limit. Both the connecting line and the pressure transducer were kept at a higher temperature than the bath to avoid condensation of the vapor. The samples were submitted to cycles of freezing in liquid nitrogen, vacuum pumping, and subsequent melting to remove dissolved gases and volatile impurities. After this stage, the liquids were further purged directly to the vacuum line for a few seconds at a time, under agitation, until the measured vapor pressure was reproducible. The measurements were made in paths of increasing and decreasing temperature, in order to reduce the possibility of a systematic error.

Density Measurements. The liquid densities were measured in an Anton Paar DMA 5000 vibrating-tube densimeter, which has an internal temperature controller with a sensitivity of $0.001 \mathrm{~K}$. The instrument was previously calibrated with water (distilled, purified with a Milli-Q 185 plus water purification system, and freshly boiled) and air at $293.150 \mathrm{~K}$, taking atmospheric pressure into account. The calibration was checked with water over the complete range of operating temperatures, and the maximum observed deviation from literature values was found to be less than $2.0 \times 10^{-5} \mathrm{~g}$ $\mathrm{cm}^{-3}$. The density of air was verified before measuring to ensure the cell was completely clean.

\section{SIMULATION METHODS}

Force Field. Molecular interactions were modeled using the OPLS-AA force field, ${ }^{35}$ where total potential energy is of the form

$$
\begin{gathered}
E_{\text {total }}=E_{\text {bonded }}+E_{\text {nonbonded }} \\
E_{\text {bonded }}=E_{\text {bond }}+E_{\text {angle }}+E_{\text {dihedral }} \\
E_{\text {nonbonded }}=E_{\text {vanderWaals }}+E_{\text {electrostatic }}
\end{gathered}
$$

$E_{\text {bond }}$ represents the energy between all covalently bonded atoms and $E_{\text {angle }}$ the energy due to bond angle bending; both terms are modeled as harmonic oscillators. $E_{\text {dihedral }}$ represents the energy of twisting bonds due to bond order and neighboring bonds and/or lone pairs of electrons, and is modeled as a Fourier series (see eq 2 below). The nonbonded terms represent the energy between all pairs of atoms. $E_{\text {van derWaals }}$ is computed using the Lennard-Jones potential (see eq 4 below), and $E_{\text {electrostatic }}$ is computed using Coulomb's law. All terms in eq 1 are defined in the Supporting Information (eqs $\mathrm{S} 1-\mathrm{S} 6$ ).

Fitting Procedures. Although OPLS-AA has not been validated for PFPEs, previous simulation studies have demonstrated its ability to accurately reproduce experimental properties for molecules containing similar functional groups, specifically hydrogenated ethers, ${ }^{35}$ perfluoroalkanes, ${ }^{36,37}$ and perfluoroalcohols. ${ }^{38,39}$ Thus, in order to minimize the number of new parameters that must be derived and help maintain transferability with the original potential, parameters were taken where possible from the current OPLS-AA force field. ${ }^{35,36,41-44}$ (Parameters for perfluoroalcohols are taken from the OPLS-AA force field database included in GROMACS 4.6.5.) ${ }^{41}$ Here, force field parameters for PFPEs were developed and tested in a three-stage process. First, an initial model (model \#1) was created from existing OPLS-AA force field parameters; the bonded parameters used in this model were tested by comparing to minimum energy molecular conformations from $a b$ initio calculations. Second, an updated model (model \#2) was constructed by modifying the bonded parameters from model \#1 to match the results from ab initio. Third, in order to match experimentally derived density vs temperature relationships, the van der Waals (VDW) parameters were optimized to create the final model (model \#3). These three models are described in detail below, and their similarities/differences are summarized in Table 1.

Table 1. Brief Summary of All Potential Models Considered in This Study ${ }^{a}$

$\begin{array}{lll} & \text { bonded parameters } & \text { nonbonded parameters } \\ \text { model \#1 } & \text { OPLS-AA force field } & \text { OPLS-AA force field } \\ \text { model \#2 } & \text { optimized } & \text { OPLS-AA force field } \\ \text { model \#3 } & \text { optimized } & \text { optimized }\end{array}$

${ }^{a}$ Model \#1 and the nonbonded parameters used by model \#2 are from the current OPLS-AA force field. ${ }^{35,36,41-44}$

An initial model for the fluorinated ether functional group (i.e., $\mathrm{CF}_{n}-\mathrm{O}-\mathrm{CF}_{n}$ ) was derived from the current OPLS-AA force field (model \#1); parameters for $\mathrm{O}$ were taken from the model for hydrogenated ethers, ${ }^{35,42}$ and parameters for $\mathrm{CF}_{n}$ were taken from the model for perfluoroalkanes. ${ }^{36,43,44}$ All force field parameters used for this model are included in the Supporting Information (Tables S1 and S2). In accordance with OPLS-AA, the charges for functional groups were taken to be transferable between molecules; ${ }^{35}$ thus, fluorinated ether groups (i.e., $\mathrm{CF}_{n}-\mathrm{O}-\mathrm{CF}_{n}$ ) were assumed to be neutral. $\mathrm{Li}$ et al. previously conducted $a b$ initio calculations to determine partial charges for perfluoromethylpropyl ether $\left(\mathrm{CF}_{3}-\mathrm{CF}_{2}-\mathrm{CF}_{2}-\mathrm{O}-\right.$ $\mathrm{CF}_{3}$ ) and reported a total charge of $-0.02 e$ for the $\mathrm{CF}_{2}-\mathrm{O}-$ $\mathrm{CF}_{3}$ group ${ }^{2}$, so this assumption seems reasonable.

The bonded parameters used for model \#1 were tested by comparing to the minimum energy molecular conformations of various PFPEs from $a b$ initio calculations at the RHF/6-31G* level. $A b$ initio calculations were performed using Gaussian 09, ${ }^{45}$ and OPLS-AA calculations were performed using the large-scale atomic/molecular massively parallel simulator (LAMMPS); ${ }^{46}$ optimized structures predicted by the force field were obtained from LAMMPS using the "minimize" function, which iteratively adjusts atomic coordinates until a local potential energy minimum is reached. If any deviations in bond lengths, angles, or dihedrals were observed, adjustments were made to the appropriate parameters. $E_{\text {bond }}$ and $E_{\text {angle }}$ parameters were optimized by adjusting equilibrium bond lengths $\left(r_{0}\right)$ and angles $\left(\theta_{0}\right)$, respectively, in order to better replicate molecular structures from $a b$ initio; $E_{\text {dihedral }}$ parameters were derived using a more complex fitting procedure, which is detailed below. All bonded parameters derived as part of this study are provided in the Supporting Information (Tables S3 and S4). 
$E_{\text {dihedral }}$ parameters were determined by fitting to energy profiles for rotation about the dihedral's central bond obtained from $a b$ initio calculations. As shown in eq 2, $E_{\text {dihedral }}$ the pure torsional energy component, includes energetic contributions from each dihedral angle involving the given bond; all other terms in eq 1 can be calculated according to the force field, thus allowing one to extract $E_{\text {dihedral }}$ from the total energy predicted by $a b$ initio. $E_{\text {dihedral }}$ parameters can then be derived according to the OPLS-AA functional form

$$
\begin{aligned}
E_{\text {dihedral }}= & \sum_{\text {dihedrals }} \frac{V_{0}}{2}+\frac{V_{1}}{2}\left[1+\cos \left(\phi-f_{1}\right)\right] \\
& +\frac{V_{2}}{2}\left[1-\cos \left(2 \phi-f_{2}\right)\right] \\
& +\frac{V_{3}}{2}\left[1+\cos \left(3 \phi-f_{3}\right)\right] \\
& +\frac{V_{4}}{2}\left[1-\cos \left(4 \phi-f_{4}\right)\right]
\end{aligned}
$$

where $V_{0}-V_{4}$ are force constants, $f_{1}-f_{4}$ are phase angles, and $\phi$ is the current value of the dihedral angle. $f_{1}-f_{4}$ are zero for the vast majority of systems studied with OPLS-AA,,$^{35,36,41}$ but in this work, some nonzero values are reported. Unlike their hydrogenated counterparts, PFPEs assume conformations that are asymmetric about ether (i.e., $\mathrm{C}-\mathrm{O}$ ) bonds ${ }^{33,34}$ and thus phase angles are required to accurately model all dihedrals with central $\mathrm{CF}_{n}-\mathrm{O}$ bonds. To fit dihedral energy profiles, leastsquares regression was performed using the open-source Multidisciplinary Design Analysis and Optimization (OpenMDAO) framework written in Python ${ }^{47}$ to minimize the differences in relative energies between $a b$ initio structures and energies calculated according to eq 2 ; in some cases, one or more Fourier terms were removed during this process because they were not needed to accurately reproduce the curve. The quality of the fit was determined as follows

$$
f_{\text {fit }}=1-\frac{\sum_{\text {conf }}\left|E-E_{\text {fit }}\right|}{\sum_{\text {conf }}|E|+\left|E_{\text {fit }}\right|}
$$

where $E_{\text {fit }}$ and $E$ are the values of the fit curve and the original curve at each conformation, respectively; an $f_{\text {fit }}$ value of 1 indicates a perfect match. The final result of optimizing the bonded parameters is model \#2.

For nonbonded interactions that are specific to PFPEs, new all-atom Lennard-Jones parameters were derived by fitting to VDW energy profiles predicted by OPLS-UA (i.e., OPLS united-atom $)^{48}$ simulations using the force field for PFPEs developed by $\mathrm{Li}$ et al., ${ }^{2,3}$ which was shown to accurately reproduce experimental densities for perfluoromethylpropyl ether $\left(\mathrm{CF}_{3}-\mathrm{CF}_{2}-\mathrm{CF}_{2}-\mathrm{O}-\mathrm{CF}_{3}\right)$, perfluoroethylmethyl ether $\left(\mathrm{CF}_{3}-\mathrm{CF}_{2}-\mathrm{O}-\mathrm{CF}_{3}\right)$, and perfluorodimethoxymethane $\left(\mathrm{CF}_{3}-\right.$ $\left.\mathrm{O}-\mathrm{CF}_{2}-\mathrm{O}-\mathrm{CF}_{3}\right)$. Taking values of $E_{\mathrm{VDW}}$ from OPLS-UA, equivalent OPLS-AA parameters can be derived according to a truncated/shifted form of the Lennard-Jones potential

$$
\begin{gathered}
E_{\mathrm{VDW}}=\sum_{i} \sum_{j} E_{\mathrm{VDW}}(i, j) \\
E_{\mathrm{VDW}}(i, j)= \begin{cases}4 \varepsilon_{i j}\left[\left(\frac{\sigma_{i j}}{r_{i j}}\right)^{12}-\left(\frac{\sigma_{i j}}{r_{i j}}\right)^{6}\right] \cdot f_{i j} & r_{i j} \leq r_{\mathrm{c}} \\
-4 \varepsilon_{i j}\left[\left(\frac{\sigma_{i j}}{r_{\mathrm{c}}}\right)^{12}-\left(\frac{\sigma_{i j}}{r_{\mathrm{c}}}\right)^{6}\right] \cdot f_{i j} & \\
0 & r_{i j}>r_{\mathrm{c}}\end{cases}
\end{gathered}
$$

where, for each $i$ and $j$ pair, $\varepsilon_{i j}$ represents the depth of the potential well, $\sigma_{i j}$ is the distance at which the interparticle potential is zero, $r_{i j}$ is the interparticle distance, and $r_{\mathrm{c}}$ is the cutoff radius for computing VDW interactions; $\varepsilon_{i j}$ and $\sigma_{i j}$ are calculated using standard geometric combining rules. $f_{i j}$ is a scaling factor; $f_{i j}=1$ unless $i$ and $j$ are separated by exactly three bonds (i.e., a $1-4$ pair, $\left.f_{i j}=0.5\right)$ or less than three bonds $\left(f_{i j}=\right.$ $0)$. Short OPLS-UA simulations $(\sim 0.2-0.3 \mathrm{~ns})$ of 256 perfluoromethylpropyl ether molecules were performed using LAMMPS $^{46}$ in the NVT ensemble (constant number of atoms, volume, and temperature) at temperatures ranging from 244 to $283 \mathrm{~K}$ and volumes chosen to match experimental densities; ${ }^{2,3,49} E_{\mathrm{VDW}}$ was calculated according to eq 4 and averaged over each simulation. Corresponding OPLS-AA simulations were then performed, and all-atom Lennard-Jones parameters were derived from eq 4 using $E_{\mathrm{VDW}}$ from the unitedatom simulations and $r_{i j}$ from the all-atom simulations. For these MD simulations and others in this work, temperature was controlled via the Nosé-Hoover thermostat ${ }^{50,51}$ with a temperature damping parameter of $100 \mathrm{fs}$. The equations of motion were integrated using the multiple time step algorithm rRESPA with time steps of 0.1 fs for bond, angle, and dihedral interactions and $1.0 \mathrm{fs}$ for van der Waals and electrostatic interactions, where electrostatics were computed using the particle-particle, particle-mesh (PPPM) algorithm with an accuracy of $10^{-6}$ relative error in forces; VDW interactions were computed using a cutoff radius of $12 \AA$. All nonbonded parameters derived here are provided in the Supporting Information (Tables S5 and S6). The result of optimizing the nonbonded parameters is model \#3, the final model.

Simulations of Gas and Liquid Phase Properties. Liquid-phase simulations to calculate the densities and enthalpies of vaporization of perfluorodiglyme and perfluorotriglyme were performed using LAMMPS. ${ }^{46}$ To calculate densities, simulations were performed in the $N p T$ ensemble (constant number of atoms, pressure, and temperature) at a pressure of $101.325 \mathrm{kPa}$ and temperatures in the range 278$343 \mathrm{~K}$ to match experiment. To calculate enthalpies of vaporization, simulations were performed in the NVT ensemble (constant number of atoms, volume, and temperature) at a temperature of $298.15 \mathrm{~K}$ and a volume that matches the experimental density. Simulations were conducted for systems composed of 256 molecules. Postequilibration trajectory lengths ranged from $\sim 2$ to $3 \mathrm{~ns}$, which were found to be sufficient in order for the simulations to converge to a steady state.

Single-molecule gas-phase simulations of perfluorodiglyme and perfluorotriglyme were also performed to calculate $\Delta H_{\text {vap }}$ at $298.15 \mathrm{~K}$. Longer postequilibration trajectory lengths were required to achieve equipartition of energy $(\sim 10-12 \mathrm{~ns})$, so 20 
individual simulations of $20 \mathrm{~ns}$ each were performed. $\Delta H_{\text {vap }}$ was calculated according to eq 5 , where $H_{\text {gas }}$ and $H_{\text {liquid }}$ are total enthalpies obtained from the gas-phase and liquid-phase molecular dynamics simulations, respectively:

$$
\Delta H_{\text {vap }}=H_{\text {gas }}-H_{\text {liquid }}
$$

\section{RESULTS AND DISCUSSION}

Experimental Vapor Pressures and Liquid Densities. In order to increase our knowledge of the thermodynamic properties of PFPEs and provide accurate data to test the new force field, vapor pressures and liquid densities of perfluorodiglyme and perfluorotriglyme were determined experimentally and molar enthalpies of vaporization calculated. The experimental vapor pressures are plotted in Figure 2 and

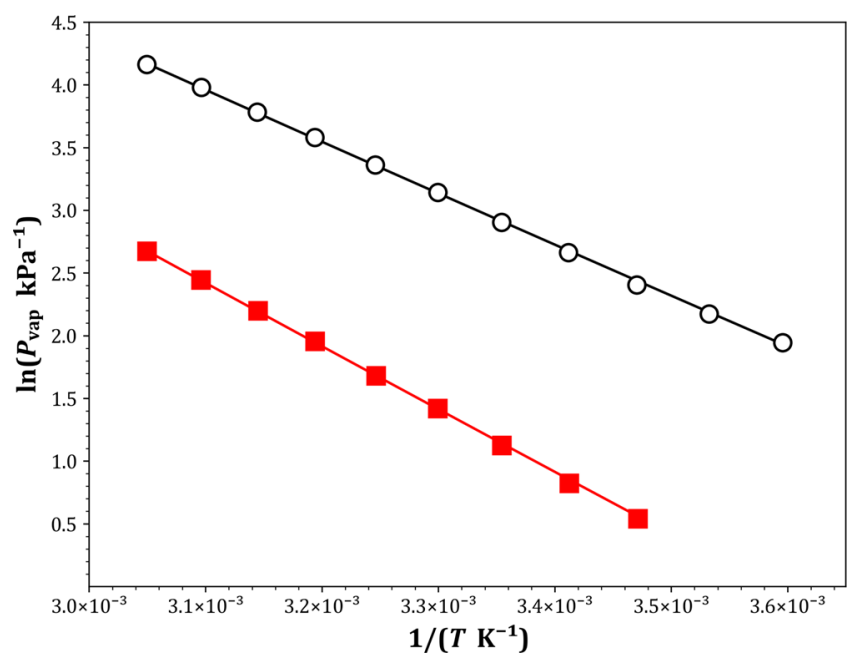

Figure 2. Experimental vapor pressure $\left(P_{\text {vap }}\right)$ of perfluorodiglyme (black $O$ ) and perfluorotriglyme (red $\mathbf{\square})$ as a function of temperature $(T)$; fitted lines were calculated using eq 6 ( $A, B$, and $C$ from Table 2$)$. This plot and the others included in this work were generated using the python plotting library matplotlib. ${ }^{52}$

tabulated in the Supporting Information (Table S7). Vapor pressures were correlated with the Antoine equation

$$
\ln \left(P_{\text {vap }}\right)=A-\frac{B}{T+C}
$$

where $P_{\text {vap }}$ is vapor pressure, $T$ is temperature, and $A, B$, and $C$ are the Antoine coefficients. The obtained coefficients reproduce the vapor pressure data within the experimental uncertainty and are presented in Table 2, along with the rootmean-square deviation (RMSD) and average percent deviation $(\Delta P / P)$ defined as

Table 2. Antoine Equation Coefficients $(A, B$, and $C)$ Used to Correlate Vapor Pressures $\left(P_{\text {vap }}\right)$ (see eq 6), Root-MeanSquare Deviation (RMSD), and Average Percent Deviation $(\Delta P / P)($ see eq 7$)$ between Measured and Calculated Vapor Pressures

\begin{tabular}{ccccccc} 
& \multicolumn{4}{c}{ Antoine equation coefficients } & & \\
\cline { 2 - 4 } compound & $A$ & $B$ & $C$ & \multirow{2}{R}{$\begin{array}{c}\text { RMSD } \\
(\mathrm{kPa})\end{array}$} & $\begin{array}{c}\Delta P / P \\
(\%)\end{array}$ \\
\cline { 2 - 4 } perfluorodiglyme & 18.054 & 4981.924 & 30.910 & 0.28 & 1.3 \\
perfluorotriglyme & 19.579 & 6050.593 & 30.058 & 0.04 & 1.0
\end{tabular}

$$
\frac{\Delta P}{P} \%=\frac{100}{n} \sum\left|\frac{P_{\exp }-P_{\text {cal }}}{P_{\exp }}\right|
$$

where $P_{\exp }$ and $P_{\text {cal }}$ are the measured and calculated vapor pressures, respectively, and $n$ is the number of experimental points. Experimental $\Delta H_{\text {vap }}$ values were then estimated from these vapor pressures using the Clausius-Clapeyron equation, assuming that $\Delta H_{\text {vap }}$ is constant in the measured temperature range and that the vapor phase behaves as an ideal gas. Values of $8.27 \pm 0.04$ and $10.11 \pm 0.04 \mathrm{kcal} \mathrm{mol}^{-1}$ were obtained for perfluorodiglyme and perfluorotriglyme, respectively.

The experimental liquid densities of perfluorodiglyme and perfluorotriglyme were measured at temperatures ranging from 278-323 and 278-343 K, respectively. These values are reported in Table 3 at $5 \mathrm{~K}$ intervals; experimental densities as a

Table 3. Experimental Densities $(\rho)$ of Perfluorodiglyme and Perfluorotriglyme at Atmospheric Pressure as a Function of Temperature $(T)^{a}$

\begin{tabular}{ccccc}
\multicolumn{2}{c}{ perfluorodiglyme } & & \multicolumn{2}{c}{ perfluorotriglyme } \\
\cline { 1 - 2 } \cline { 5 - 5 }$T(\mathrm{~K})$ & $\rho\left(\mathrm{g} \mathrm{cm}^{-3}\right)$ & & $T(\mathrm{~K})$ & $\rho\left(\mathrm{g} \mathrm{cm}^{-3}\right)$ \\
278.152 & 1.669397 & & 278.156 & 1.700303 \\
283.144 & 1.654497 & & 283.148 & 1.686951 \\
288.145 & 1.639417 & & 288.146 & 1.673491 \\
293.146 & 1.624188 & & 293.147 & 1.659941 \\
298.146 & 1.608785 & & 298.146 & 1.646300 \\
303.146 & 1.593194 & & 303.146 & 1.632551 \\
308.145 & 1.577403 & & 308.145 & 1.618687 \\
313.145 & 1.561382 & & 313.145 & 1.604700 \\
318.146 & 1.545111 & & 318.146 & 1.590572 \\
323.144 & 1.528580 & & 323.145 & 1.576303 \\
& & & 328.145 & 1.561870 \\
& & & 333.145 & 1.547259 \\
& & 338.146 & 1.532454 \\
& & 343.145 & 1.517440
\end{tabular}

${ }^{a}$ Standard uncertainties are $0.01 \mathrm{~K}$ for $T$ and $2.0 \times 10^{-5} \mathrm{~g} \mathrm{~cm}^{-3}$ for $\rho$.

function of temperature at $1 \mathrm{~K}$ intervals are included in the Supporting Information (Table S8). Third degree polynomial equations (eq 8) were fitted to the experimental densities in the measured temperature range, and results are reported in Table 4.

$$
\rho=a_{3}\left(\frac{T}{100}\right)^{3}+a_{2}\left(\frac{T}{100}\right)^{2}+a_{1}\left(\frac{T}{100}\right)+a_{0}
$$

Table 4. Fitting Constants $\left(a_{0}-a_{3}\right)$ Used for Third Degree Polynomial Equations (eq 8)

\begin{tabular}{ccccc} 
compound & $a_{3} \times 10^{2}$ & $a_{2} \times 10^{1}$ & $a_{1} \times 10^{1}$ & $a_{0} \times 10^{0}$ \\
perfluorodiglyme & -2.560245 & 1.911759 & -7.669885 & 2.874669 \\
perfluorotriglyme & -1.591910 & 1.216717 & -5.748068 & 2.700407 \\
\hline
\end{tabular}

Force Field Development. Optimization of Bonded Parameters. As discussed above, a three-stage process was employed to develop and test force field parameters for PFPEs. First, an initial model for the fluorinated ether functional group (i.e., $\mathrm{CF}_{n}-\mathrm{O}-\mathrm{CF}_{n}$ ) was derived from the current OPLS-AA force field (model \#1); parameters for $\mathrm{O}$ were taken from the model for hydrogenated ethers, ${ }^{35,42}$ and parameters for $\mathrm{CF}_{n}$ were taken from the model for perfluoroalkanes. ${ }^{36,43,44}$ To 
determine whether this model is adequate for PFPEs, the bonded parameters were tested through the ability of the force field to replicate minimum energy molecular conformations from QM calculations. This comparison showed that the $E_{\text {bond }}$ and $E_{\text {angle }}$ parameters were generally in good agreement with $a b$ initio results $\left(\sim 0.03 \AA\right.$ and $\sim 2.5^{\circ}$ error, respectively), but equilibrium bond lengths $\left(r_{0}\right)$ and angles $\left(\theta_{0}\right)$ were modified to match values from QM in the few cases where deviations were greater than $0.02 \AA$ or $1.0^{\circ}$, respectively. One example is the $\mathrm{C}_{\mathrm{F}}-\mathrm{O}$ bond, where $r_{0}$ was changed to $1.36 \AA$ from the equilibrium value of $1.41 \AA$ used to model $\mathrm{C}_{\mathrm{H}}-\mathrm{O}$ bonds in hydrogenated ethers. ${ }^{42}$ This observation is consistent with experiments and prior QM calculations, which showed that the $\mathrm{C}-\mathrm{O}$ bond in perfluorodimethyl ether $\left(\mathrm{CF}_{3}-\mathrm{O}-\mathrm{CF}_{3}\right)$ is shortened $\left(r_{0} \approx 1.37 \AA\right)$ compared to dimethyl ether $\left(\mathrm{CH}_{3}-\right.$ $\left.\mathrm{O}-\mathrm{CH}_{3}\right)\left(r_{0} \approx 1.43 \AA\right) .{ }^{33,34}$ Another example is the $\mathrm{C}_{\mathrm{F}}-\mathrm{O}-\mathrm{C}_{\mathrm{F}}$ angle, whose equilibrium value $\left(\theta_{0}\right)$ was increased to $121.4^{\circ}$ from the equilibrium value of $109.5^{\circ}$ used to model $\mathrm{C}_{\mathrm{H}}-\mathrm{O}-\mathrm{C}_{\mathrm{H}}$ angles in hydrogenated ethers. ${ }^{42}$ This result is also consistent with experiments and prior QM calculations, which have shown that the $\mathrm{C}-\mathrm{O}-\mathrm{C}$ angle in perfluorodimethyl ether is significantly increased $\left(\theta_{0} \approx 120^{\circ}\right)$ compared to dimethyl ether $\left(\theta_{0} \approx 112^{\circ}\right) .33,34,53,54$ In contrast with bonds and angles, the dihedral parameters taken from the current OPLS-AA force field generally failed to accurately predict molecular structures, with errors up to $\sim 35^{\circ}$ in the minimum energy conformations.

Optimized $E_{\text {dihedral }}$ parameters were therefore determined after equilibrium bond lengths $\left(r_{0}\right)$ and angles $\left(\theta_{0}\right)$ were updated to better replicate molecular conformations from QM. Note that the fitting procedure requires all energetic components of $E_{\text {total }}$ with the exception of $E_{\text {dihedral }}$ (see eq 1) to be calculated from the force field itself; these energies were calculated using the $E_{\text {nonbonded }}$ parameters from model \#1 and optimized $E_{\text {bond }}$ and $E_{\text {angle }}$ parameters. As previously mentioned, PFPEs adopt conformations that are asymmetric about ether (i.e., C-O) bonds, ${ }^{33,34}$ so in order to accurately model dihedrals with central $\mathrm{CF}_{n}-\mathrm{O}$ bonds using eq 2, nonzero phase angles $\left(f_{1}-f_{4}\right)$ are required. For example, if we consider the most energetically favorable conformations of dimethyl ether (Figure 3A) and perfluorodimethyl ether (Figure 3B), the $\mathrm{H}-$ $\mathrm{C}_{\mathrm{H}}-\mathrm{O}-\mathrm{C}_{\mathrm{H}}$ dihedral in dimethyl ether assumes a staggered conformation as expected (i.e., hydrogen atoms on the proximal carbon are arranged to maximize their distances from each other and the other carbon), while the $\mathrm{F}-\mathrm{C}_{\mathrm{F}}-\mathrm{O}-\mathrm{C}_{\mathrm{F}}$ dihedral in perfluorodimethyl ether increases by a further $\sim 17^{\circ}$; this result is consistent with the experimental observation of $14^{\circ}, 33$ and prior $\mathrm{QM}$ calculations which predict values ranging from 15 to $17^{\circ} .^{34}$ Figure $3 \mathrm{C}$ compares $\mathrm{H}-\mathrm{C}_{\mathrm{H}}-\mathrm{O}-\mathrm{C}_{\mathrm{H}}$ and $\mathrm{F}-$ $\mathrm{C}_{\mathrm{F}}-\mathrm{O}-\mathrm{C}_{\mathrm{F}}$ dihedral energy profiles obtained from full rotations of dimethyl ether and perfluorodimethyl ether, respectively, about one of the central $\mathrm{C}-\mathrm{O}$ bonds; although the curves are similar in shape, in the case of $\mathrm{F}-\mathrm{C}_{\mathrm{F}}-\mathrm{O}-\mathrm{C}_{\mathrm{F}}$, the positions of all local minima and maxima are shifted right by $\sim 17^{\circ}$. Note that the use of nonzero phase angles with eq 2 improved $f_{\text {fit }}$ (see eq 3 ) for the $\mathrm{F}-\mathrm{C}_{\mathrm{F}}-\mathrm{O}-\mathrm{C}_{\mathrm{F}}$ dihedral energy profile shown in Figure 3C from $0.783\left(\sim 1.12 \mathrm{kcal} \mathrm{mol}^{-1}\right.$ error $)$ to 0.975 $\left(\sim 0.02 \mathrm{kcal} \mathrm{mol}^{-1}\right.$ error$)$. For all types of dihedrals with parameters derived as part of this study, QM molecular structures and energy profiles are provided in the Supporting Information (Figures S1-S8). From this data, we note that each dihedral with a central $\mathrm{CF}_{n}-\mathrm{O}$ bond (e.g., $\mathrm{F}-\mathrm{C}_{\mathrm{F}}-\mathrm{O}-\mathrm{C}_{\mathrm{F}}$ ) exhibits a phase shift of $\sim 17-20^{\circ}$.
A

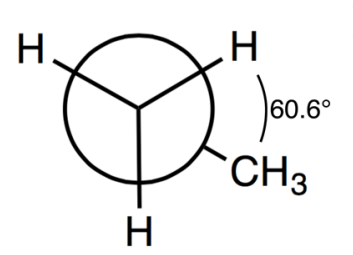

B
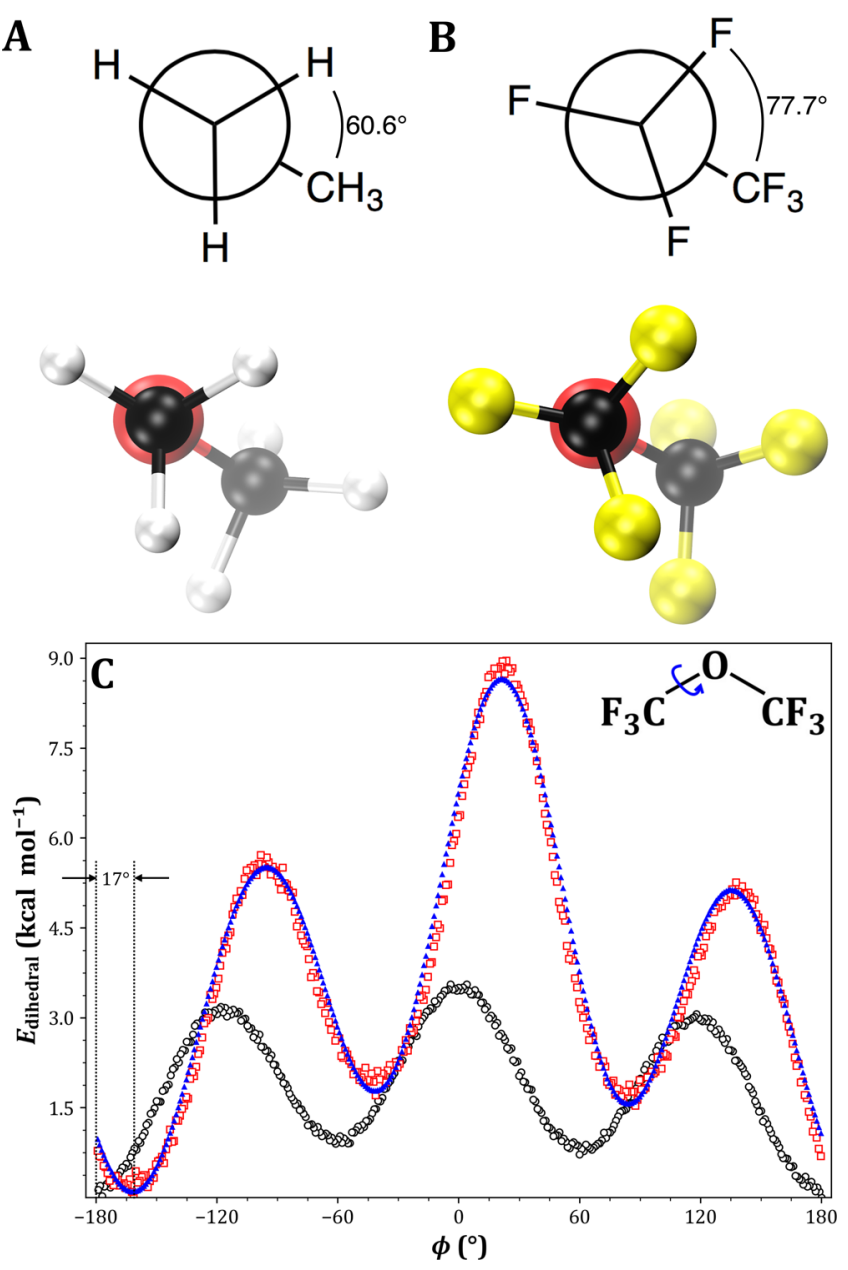

Figure 3. Gas-phase structures (A and $\mathrm{B}$ ) and conformational energetics $(\mathrm{C})$ of dimethyl ether $\left(\mathrm{CH}_{3}-\mathrm{O}-\mathrm{CH}_{3}\right)$ and perfluorodimethyl ether $\left(\mathrm{CF}_{3}-\mathrm{O}-\mathrm{CF}_{3}\right)$ predicted by ab initio calculations at the RHF/6-31G* level. Minimum energy conformations for (A) dimethyl ether and (B) perfluorodimethyl ether are visualized by Newman projections across one central $\mathrm{C}-\mathrm{O}$ bond and equivalent simulation snapshots, which were generated using the Visual Molecular Dynamics (VMD) software; ${ }^{55}$ carbon atoms are shown in black, oxygen in red, and fluorine in yellow. (C) Dihedral energy profiles for $\mathrm{H}-\mathrm{C}_{\mathrm{H}}-\mathrm{O}-$ $\mathrm{C}_{\mathrm{H}}$ (black $\mathrm{O}$ ) and $\mathrm{F}-\mathrm{C}_{\mathrm{F}}-\mathrm{O}-\mathrm{C}_{\mathrm{F}}($ red $\square$ ) obtained from full rotations of dimethyl ether and perfluorodimethyl ether (shown in inset diagram) about one central $\mathrm{C}-\mathrm{O}$ bond. For $\mathrm{F}-\mathrm{C}_{\mathrm{F}}-\mathrm{O}-\mathrm{C}_{\mathrm{F}}$, the curve obtained by fitting the dihedral energy profile according to eq 2 is shown (blue $\boldsymbol{\Delta}$ ), where $f_{\text {fit }}=0.975$ (see eq 3 ).

As shown in Table 5, optimized molecular structures obtained from QM calculations and MD simulations using the new $E_{\text {dihedral }}$ parameters for PFPEs (model \#2) demonstrate excellent agreement; the predicted values for all dihedral angles deviate by $\leq 3^{\circ}$, and several show deviations below $1^{\circ}$. Dihedral energy profiles from MD also agree closely with $\mathrm{QM}$, with values of $f_{\text {fit }}$ approaching 1 . The average absolute deviation in relative energy is $<0.5 \mathrm{kcal} \mathrm{mol}^{-1}$ for all molecules in the conformations that were sampled, with many demonstrating differences below $0.1 \mathrm{kcal} \mathrm{mol}^{-1}$. The minimum energy molecular conformations of perfluorodiglyme, perfluorotriglyme, Dupont Krytox $\left(\mathrm{F}-\mathrm{CF}\left(\mathrm{CF}_{3}\right)-\mathrm{CF}_{2}-\mathrm{O}\right)_{m=2}-\mathrm{CF}_{2}-$ $\left.\mathrm{CF}_{3}\right)$, ${ }^{5}$ and Fomblin $\mathrm{Zdol}\left(\mathrm{HO}-\mathrm{CH}_{2}-\mathrm{CF}_{2}-\mathrm{O}-\left(\mathrm{CF}_{2}-\mathrm{CF}_{2}-\right.\right.$ $\left.\mathrm{O})_{m=1}-\left(\mathrm{CF}_{2}-\mathrm{O}\right)_{n=1}-\mathrm{CF}_{2}-\mathrm{CH}_{2}-\mathrm{OH}\right)^{12}$ predicted by $\mathrm{QM}$ and $\mathrm{MD}$ are also compared in Table 6; these molecules were chosen because they are relatively small ( $\leq 30$ atoms), provide 
Table 5. Comparison of Minimum Energy Molecular Structures and Conformational Energies Predicted by Ab Initio Quantum Mechanical (QM) Calculations at the RHF/6-31G* Level and Molecular Dynamics (MD) Simulations Using the New All-Atom Potential for PFPEs (Model \#2) ${ }^{a}$

\begin{tabular}{|c|c|c|c|c|c|}
\hline \multirow[b]{2}{*}{ compound } & \multirow[b]{2}{*}{ dihedral } & \multicolumn{2}{|c|}{ optimized molecular structures } & \multicolumn{2}{|c|}{ conformational energies } \\
\hline & & $\phi_{\mathrm{QM}}(\operatorname{deg})$ & $\phi_{\mathrm{MD}}(\operatorname{deg})$ & $\Delta E_{\text {dihedral }}$ & $f_{\text {fit }}$ \\
\hline $\mathrm{CF}_{3}-\mathrm{O}-\mathrm{CF}_{3}$ & $\mathrm{~F}-\mathrm{C}_{\mathrm{F}}-\mathrm{O}-\mathrm{C}_{\mathrm{F}}$ & -163.2602 & -163.5480 & 0.180 & 0.975 \\
\hline $\mathrm{CF}_{3}-\mathrm{O}-\mathrm{CF}_{2}-\mathrm{O}-\mathrm{CF}_{3}$ & $\mathrm{O}-\mathrm{C}_{\mathrm{F}}-\mathrm{O}-\mathrm{C}_{\mathrm{F}}$ & 160.3303 & 160.3320 & 0.288 & 0.972 \\
\hline $\mathrm{CF}_{3}-\mathrm{CF}_{2}-\mathrm{O}-\mathrm{CF}_{3}$ & $\mathrm{C}_{\mathrm{F}}-\mathrm{C}_{\mathrm{F}}-\mathrm{O}-\mathrm{C}_{\mathrm{F}}$ & 162.7903 & 161.9460 & 0.252 & 0.986 \\
\hline $\mathrm{CF}_{3}-\mathrm{CF}_{2}-\mathrm{O}-\mathrm{CF}_{3}$ & $\mathrm{O}-\mathrm{C}_{\mathrm{F}}-\mathrm{C}_{\mathrm{F}}-\mathrm{F}$ & 61.2819 & 61.4663 & 0.037 & 0.993 \\
\hline $\mathrm{CF}_{3}-\mathrm{O}-\mathrm{CF}_{2}-\mathrm{CF}_{2}-\mathrm{O}-\mathrm{CF}_{3}$ & $\mathrm{O}-\mathrm{C}_{\mathrm{F}}-\mathrm{C}_{\mathrm{F}}-\mathrm{O}$ & 180.0346 & 179.3200 & 0.100 & 0.957 \\
\hline $\mathrm{CF}_{3}-\mathrm{CF}_{2}-\mathrm{CF}_{2}-\mathrm{O}-\mathrm{CF}_{3}$ & $\mathrm{O}-\mathrm{C}_{\mathrm{F}}-\mathrm{C}_{\mathrm{F}}-\mathrm{C}_{\mathrm{F}}$ & -60.1622 & -60.3006 & 0.092 & 0.976 \\
\hline $\mathrm{CH}_{3}-\mathrm{CF}_{2}-\mathrm{O}-\mathrm{CF}_{3}$ & $\mathrm{C}_{\mathrm{H}}-\mathrm{C}_{\mathrm{F}}-\mathrm{O}-\mathrm{C}_{\mathrm{F}}$ & 163.7719 & 165.3630 & 0.336 & 0.980 \\
\hline $\mathrm{CF}_{3}-\mathrm{O}-\mathrm{CF}_{2}-\mathrm{CH}_{2}-\mathrm{OH}$ & $\mathrm{O}-\mathrm{C}_{\mathrm{F}}-\mathrm{C}_{\mathrm{H}}-\mathrm{H}$ & 59.5925 & 59.2199 & 0.015 & 0.997 \\
\hline $\mathrm{CF}_{3}-\mathrm{O}-\mathrm{CF}_{2}-\mathrm{CH}_{2}-\mathrm{OH}$ & $\mathrm{O}-\mathrm{C}_{\mathrm{F}}-\mathrm{C}_{\mathrm{H}}-\mathrm{O}$ & -179.2433 & -176.1450 & 0.015 & 0.994 \\
\hline
\end{tabular}

${ }^{a}$ Bonded parameters were derived in this work, and nonbonded parameters are from the current OPLS-AA force field. ${ }^{35,36}$ For all optimized structures, predicted values of dihedral angles $\left(\phi_{\mathrm{QM}}\right.$ and $\left.\phi_{\mathrm{MD}}\right)$ are shown. For all energy profiles, average absolute deviation $\left(\Delta E_{\text {dihedral }}\right)$ in kcal mol ${ }^{-1}$ and $f_{\text {fit }}$ (see eq 3$)$ are provided; $f_{\text {fit }}$ indicates the quality of the fit (i.e., $f_{\text {fit }}=1$ for a perfect match).

Table 6. Comparison of Optimized Molecular Structures for Perfluorodiglyme $\left(\mathrm{CF}_{3}-\mathrm{O}-\left(\mathrm{CF}_{2}-\mathrm{CF}_{2}-\mathrm{O}\right)_{2}-\mathrm{CF}_{3}\right)$, Perfluorotriglyme $\left(\mathrm{CF}_{3}-\mathrm{O}-\left(\mathrm{CF}_{2}-\mathrm{CF}_{2}-\mathrm{O}\right)_{3}-\mathrm{CF}_{3}\right)$, Dupont Krytox $\left.\left(\mathrm{F}-\mathrm{CF}\left(\mathrm{CF}_{3}\right)-\mathrm{CF}_{2}-\mathrm{O}\right)_{m=2}-\mathrm{CF}_{2}-\mathrm{CF}_{3}\right)^{5}$, and Fomblin $\mathrm{Zdol}$ $\left(\mathrm{HO}-\mathrm{CH}_{2}-\mathrm{CF}_{2}-\mathrm{O}-\left(\mathrm{CF}_{2}-\mathrm{CF}_{2}-\mathrm{O}\right)_{m=1}-\left(\mathrm{CF}_{2}-\mathrm{O}\right)_{n=1}-\mathrm{CF}_{2}-\mathrm{CH}_{2}-\mathrm{OH}\right)^{12}$ from $\mathrm{Ab}$ Initio Quantum Mechanical (QM) Calculations at the RHF/6-31G* Level and Molecular Dynamics (MD) Simulations Using the New All-Atom Potential for PFPEs (Model \#2)

\begin{tabular}{|c|c|c|c|c|c|}
\hline \multicolumn{3}{|c|}{ perfluorodiglyme } & \multicolumn{3}{|c|}{ perfluorotriglyme } \\
\hline dihedral & $\phi_{\mathrm{QM}}(\operatorname{deg})$ & $\phi_{\mathrm{MD}}(\mathrm{deg})$ & dihedral & $\phi_{\mathrm{QM}}(\operatorname{deg})$ & $\phi_{\mathrm{MD}}(\mathrm{deg})$ \\
\hline $\mathrm{F}-\mathrm{C}_{\mathrm{F}}-\mathrm{O}-\mathrm{C}_{\mathrm{F}}$ & 78.1668 & 78.0864 & $\mathrm{~F}-\mathrm{C}_{\mathrm{F}}-\mathrm{O}-\mathrm{C}_{\mathrm{F}}$ & 79.0002 & 79.2651 \\
\hline $\mathrm{C}_{\mathrm{F}}-\mathrm{C}_{\mathrm{F}}-\mathrm{O}-\mathrm{C}_{\mathrm{F}}$ & 162.6716 & 161.9321 & $\mathrm{C}_{\mathrm{F}}-\mathrm{C}_{\mathrm{F}}-\mathrm{O}-\mathrm{C}_{\mathrm{F}}$ & 161.9347 & 160.7466 \\
\hline $\mathrm{O}-\mathrm{C}_{\mathrm{F}}-\mathrm{C}_{\mathrm{F}}-\mathrm{F}$ & 59.6873 & 60.0857 & $\mathrm{O}-\mathrm{C}_{\mathrm{F}}-\mathrm{C}_{\mathrm{F}}-\mathrm{F}$ & 59.6878 & 59.7487 \\
\hline $\mathrm{O}-\mathrm{C}_{\mathrm{F}}-\mathrm{C}_{\mathrm{F}}-\mathrm{O}$ & 179.9712 & 178.4920 & $\mathrm{O}-\mathrm{C}_{\mathrm{F}}-\mathrm{C}_{\mathrm{F}}-\mathrm{O}$ & 179.9185 & 178.8992 \\
\hline \multicolumn{3}{|c|}{ Krytox } & \multicolumn{3}{|c|}{ Zdol } \\
\hline dihedral & $\phi_{\mathrm{QM}}(\operatorname{deg})$ & $\phi_{\mathrm{MD}}(\mathrm{deg})$ & dihedral & $\phi_{\mathrm{QM}}(\operatorname{deg})$ & $\phi_{\mathrm{MD}}(\mathrm{deg})$ \\
\hline $\mathrm{F}-\mathrm{C}_{\mathrm{F}}-\mathrm{O}-\mathrm{C}_{\mathrm{F}}$ & 78.3942 & 78.8019 & $\mathrm{~F}-\mathrm{C}_{\mathrm{F}}-\mathrm{O}-\mathrm{C}_{\mathrm{F}}$ & 78.8980 & 78.1652 \\
\hline $\mathrm{C}_{\mathrm{F}}-\mathrm{C}_{\mathrm{F}}-\mathrm{O}-\mathrm{C}_{\mathrm{F}}$ & 162.3297 & 161.1301 & $\mathrm{O}-\mathrm{C}_{\mathrm{F}}-\mathrm{O}-\mathrm{C}_{\mathrm{F}}$ & 163.4397 & 161.3645 \\
\hline $\mathrm{O}-\mathrm{C}_{\mathrm{F}}-\mathrm{C}_{\mathrm{F}}-\mathrm{F}$ & 61.1078 & 61.0142 & $\mathrm{C}_{\mathrm{F}}-\mathrm{C}_{\mathrm{F}}-\mathrm{O}-\mathrm{C}_{\mathrm{F}}$ & 162.2576 & 161.9139 \\
\hline \multirow[t]{5}{*}{$\mathrm{O}-\mathrm{C}_{\mathrm{F}}-\mathrm{C}_{\mathrm{F}}-\mathrm{C}_{\mathrm{F}}$} & 177.6503 & 178.6288 & $\mathrm{O}-\mathrm{C}_{\mathrm{F}}-\mathrm{C}_{\mathrm{F}}-\mathrm{F}$ & 59.6550 & 59.9245 \\
\hline & & & $\mathrm{O}-\mathrm{C}_{\mathrm{F}}-\mathrm{C}_{\mathrm{F}}-\mathrm{O}$ & 179.9862 & 178.7207 \\
\hline & & & $\mathrm{C}_{\mathrm{H}}-\mathrm{C}_{\mathrm{F}}-\mathrm{O}-\mathrm{C}_{\mathrm{F}}$ & 163.2963 & 167.3211 \\
\hline & & & $\mathrm{O}-\mathrm{C}_{\mathrm{F}}-\mathrm{C}_{\mathrm{H}}-\mathrm{H}$ & 62.4655 & 62.5462 \\
\hline & & & $\mathrm{O}-\mathrm{C}_{\mathrm{F}}-\mathrm{C}_{\mathrm{H}}-\mathrm{OH}$ & 175.8916 & 176.8589 \\
\hline
\end{tabular}

${ }^{a}$ Bonded parameters were derived in this work, and nonbonded parameters are from the current OPLS-AA force field. ${ }^{35,36}$ Predicted values of dihedral angles $\left(\phi_{\mathrm{QM}}\right.$ and $\left.\phi_{\mathrm{MD}}\right)$ are shown for all optimized structures.

Table 7. Total Enthalpies of Vaporization $\left(\Delta \mathrm{H}_{\mathrm{vap}}\right)$ in $\mathrm{kcal} \mathrm{mol}^{-1}$ for Perfluorodiglyme $\left(\mathrm{CF}_{3}-\mathrm{O}-\left(\mathrm{CF}_{2}-\mathrm{CF}_{2}-\mathrm{O}\right)_{2}-\mathrm{CF}_{3}\right)$ and Perfluorotriglyme $\left(\mathrm{CF}_{3}-\mathrm{O}-\left(\mathrm{CF}_{2}-\mathrm{CF}_{2}-\mathrm{O}\right)_{3}-\mathrm{CF}_{3}\right)$ at $\mathrm{T}=298.15 \mathrm{~K}$ Determined from Experiments and Simulations Using Three Different Models ${ }^{a}$

\begin{tabular}{|c|c|c|c|c|}
\hline compound & experiment & model \#1 & model \#2 & model \#3 \\
\hline perfluorodiglyme & $8.27 \pm 0.04$ & $5.78 \pm 0.79$ & $6.02 \pm 0.90$ & $8.26 \pm 0.31$ \\
\hline perfluorotriglyme & $10.11 \pm 0.04$ & $8.99 \pm 0.81$ & $9.14 \pm 0.77$ & $9.88 \pm 0.35$ \\
\hline
\end{tabular}

${ }^{a}$ Model \#1 and the nonbonded parameters used by model \#2 are from the current OPLS-AA force field; ${ }^{35,36,41-44}$ bonded parameters for models \#2 and \#3 and nonbonded parameters for model \#3 were derived as part of this work. Error bars represent one standard deviation.

representative coverage of the functional groups considered in this study, and have practical applications. ${ }^{1,5,6,12}$ Average absolute deviations between structures predicted by QM and MD calculations are $\sim 0.01 \AA$ for bond lengths, $\sim 0.5^{\circ}$ for angles, and $\sim 0.4^{\circ}$ for dihedrals.

Optimization of Nonbonded Parameters. Following optimization of the bonded parameters, the nonbonded parameters were tested by comparing to the experimental enthalpies of vaporization and densities of perfluorodiglyme and perfluorotriglyme. Models \#1 and \#2 were shown to be inadequate for these PFPEs (see Table 7 and Figure 4). Prior simulation studies have demonstrated that both $\Delta H_{\text {vap }}$ and $\rho$ are almost exclusively associated with nonbonded interactions. $^{35,48,56}$ For example, Wang et al. recently showed that $\Delta H_{\text {vap }}$ and $\rho$ calculated using the AMBER force field approach experimental values synchronously as a function of LennardJones parameters $\sigma$ and $\varepsilon$ (see eq 4). ${ }^{56}$ For some molecules, atomic partial charges $(q)$ also play a role in determining $\Delta H_{\text {vap }}$ 

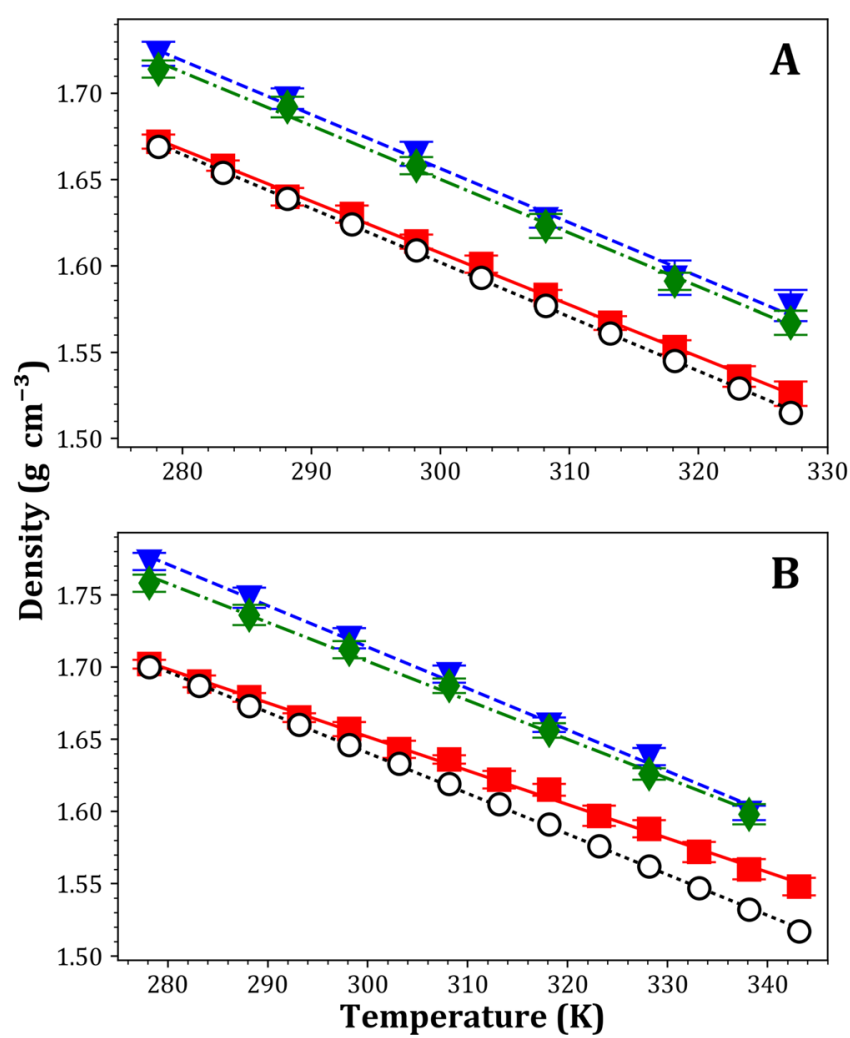

Figure 4. Density $(\rho)$ of $(\mathrm{A})$ perfluorodiglyme $\left(\mathrm{CF}_{3}-\mathrm{O}-\left(\mathrm{CF}_{2}-\mathrm{CF}_{2}-\right.\right.$ $\left.\mathrm{O})_{2}-\mathrm{CF}_{3}\right)$ and $(\mathrm{B})$ perfluorotriglyme $\left(\mathrm{CF}_{3}-\mathrm{O}-\left(\mathrm{CF}_{2}-\mathrm{CF}_{2}-\mathrm{O}\right)_{3}-\right.$ $\mathrm{CF}_{3}$ ) as a function of temperature $(T)$ from experiments (black $\mathrm{O}$ ) and simulations using three different models: model \#1 (blue $\boldsymbol{\nabla}$ ), model \#2 (green $\downarrow$ ), and model \#3 (red $\mathbf{\square}$ ). Model \#1 and the nonbonded parameters used by model \#2 are from the current OPLSAA force field; ${ }^{35,36,41-44}$ bonded parameters for models \#2 and \#3 and nonbonded parameters for model \#3 were derived as part of this work. Error bars represent one standard deviation, and lines are provided as a visual guide only.

and $\rho$, albeit a less important one. ${ }^{35,48}$ Thus, adjustments to the Lennard-Jones parameters were made in an attempt to better replicate experimental values of $\Delta H_{\text {vap }}$ and $\rho$.

All-atom Lennard-Jones parameters have not previously been developed specifically for PFPEs, but the united-atom force field created by $\mathrm{Li}$ et al. was shown to accurately reproduce experimental densities for several small perfluoroethers. ${ }^{2,3}$ As previously described, all-atom Lennard-Jones parameters have been derived according to eq 4 by taking values of $E_{\mathrm{VDW}}$ from OPLS-UA simulations of perfluoromethylpropyl ether. Li et al. used previously derived united-atom Lennard-Jones parameters for perfluoroalkanes ${ }^{57}$ to model $\mathrm{CF}_{2}$ and $\mathrm{CF}_{3}$, and derived new parameters for $\mathrm{O}$ in order to reproduce the experimentally measured phase diagram of perfluoromethylpropyl ether. ${ }^{2,3} \mathrm{~A}$ similar approach has been taken here: Lennard-Jones parameters from the OPLS-AA model for perfluoroalkanes ${ }^{36}$ were used to model $\mathrm{C}$ and $\mathrm{F}$, and new parameters for $\mathrm{O}$ were determined by fitting to $E_{\mathrm{VDW}}$ profiles predicted by the Li et al. force field to create model \#3; for $\mathrm{O}$, the Lennard-Jones parameters $\sigma$ and $\varepsilon$ were changed to $2.790 \AA$ and $0.152 \mathrm{kcal}$ $\mathrm{mol}^{-1}$, respectively, from the values used for $\mathrm{O}$ in the OPLS-AA model for hydrogenated ethers ${ }^{35}(2.900 \AA$ and $0.140 \mathrm{kcal}$ $\mathrm{mol}^{-1}$ ). Following this procedure, average absolute deviations between values of $E_{\mathrm{VDW}}$ predicted by the parent OPLS-UA simulations and OPLS-AA simulations using the updated
Lennard-Jones parameters were reasonably low $(\sim 0.52 \mathrm{kcal}$ molecule $\left.{ }^{-1}\right)$. We note that introducing new parameters for all atoms $(\mathrm{C}, \mathrm{F}$, and $\mathrm{O})$ might improve the quality of the fit; however, one important goal of this work is to maintain transferability with the original OPLS-AA potential, in part by minimizing the number of new parameters that must be introduced.

$\Delta H_{\text {vap }}$ and $\rho$ for perfluorodiglyme and perfluorotriglyme have been calculated according to the final model for PFPEs (model \#3) and compared to experiments and simulations using models \#1 and \#2; values of $\Delta H_{\text {vap }}$ at a temperature of 298.15 $\mathrm{K}$ are given in Table 7 , and $\rho$ is shown as a function of temperature for perfluorodiglyme (Figure 4A) and perfluorotriglyme (Figure 4B). The final model agrees closely with experiments and demonstrates significant improvement over models \#1 and \#2. Note that values of $\Delta H_{\text {vap }}$ and $\rho$ predicted by models \#1 and \#2 are so similar that in many cases the deviation is not statistically significant; both models use the same nonbonded parameters, so this observation is consistent with results from prior simulation studies which have shown that both $\Delta H_{\text {vap }}$ and $\rho$ are almost exclusively associated with nonbonded interactions. ${ }^{35,48,56}$ Model \#3 reproduces experimental $\Delta H_{\text {vap }}$ and $\rho$ accurately for perfluorodiglyme and perfluorotriglyme, with an average absolute error of $\sim 0.145 \mathrm{kcal}$ $\mathrm{mol}^{-1}(\sim 1.5 \%)$ for $\Delta H_{\text {vap }}$ and $\sim 0.012 \mathrm{~g} \mathrm{~cm}^{-3}(\sim 0.7 \%)$ for $\rho$. The model slightly overpredicts $\rho$, particularly at higher temperatures, and slightly underpredicts $\Delta H_{\text {vap }}$ for both PFPEs. Excellent agreement with experiment is observed for the density of perfluorodiglyme ( $\sim 0.4 \%$ error $)$, and satisfactory agreement is also observed for perfluorotriglyme $(\sim 1.0 \%$ error). In the case of $\Delta H_{\text {vap}}$, better agreement with experiment is also observed for perfluorodiglyme $(\sim 0.7 \%$ error $)$ than perfluorotriglyme ( $2.3 \%$ error).

Comparison to Other Substances. Figure 5 compares perfluorodiglyme and perfluorotriglyme $\Delta H_{\text {vap }}$ values calculated from experimental vapor pressures to those of their hydro-

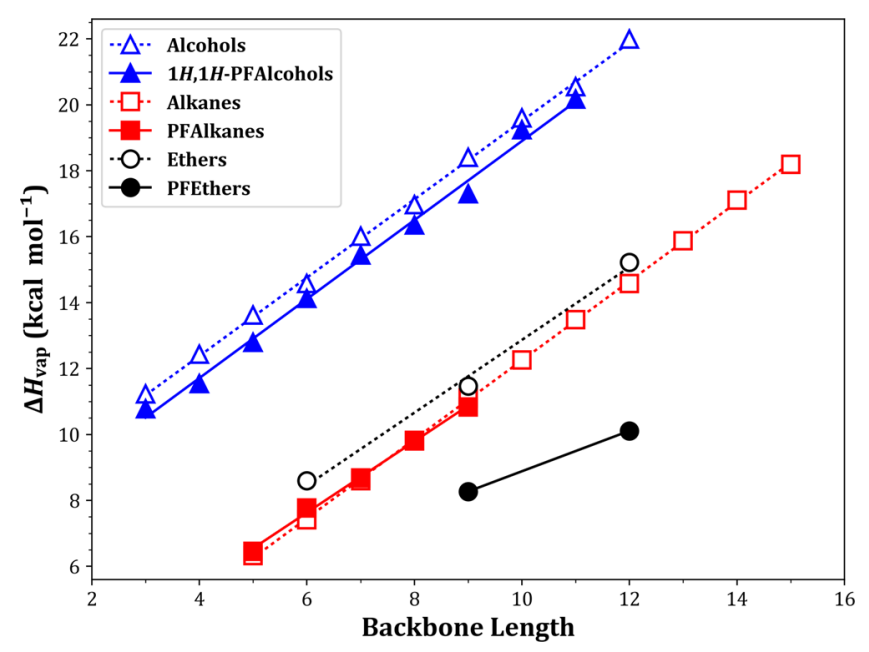

Figure 5. Enthalpies of vaporization $\left(\Delta H_{\text {vap }}\right)$ derived from experiments on families of hydrogenated and fluorinated compounds as a function of backbone length $(n)$. Values from the literature are given for hydrogenated ethers $\left(\mathrm{CH}_{3}-\mathrm{O}-\left(\mathrm{CH}_{2}-\mathrm{CH}_{2}-\mathrm{O}\right)_{(n-3) / 3}-\mathrm{CH}_{3}\right),{ }_{n}$ nalkanes $\left(\mathrm{CH}_{3}-\left(\mathrm{CH}_{2}\right)_{n-2}-\mathrm{CH}_{3}\right),{ }^{58}$ perfluoroalkanes $\left(\mathrm{CF}_{3}-\left(\mathrm{CF}_{2}\right)_{n-2}-\right.$ $\left.\mathrm{CF}_{3}\right),{ }^{58} n$-alcohols $\left(\mathrm{CH}_{3}-\left(\mathrm{CH}_{2}\right)_{n-1}-\mathrm{OH}\right),{ }^{58}$ and $1 \mathrm{H}, 1 \mathrm{H}$-perfluoroalcohols $\left(\mathrm{CF}_{3}-\left(\mathrm{CF}_{2}\right)_{n-2}-\mathrm{CH}_{2}-\mathrm{OH}\right){ }^{59,60}$ Lines are provided as a visual guide only. 
Table 8. Densities $(\rho)$ and Total Enthalpies of Vaporization $\left(\Delta H_{\text {vap }}\right)$ Derived from Experiments and Simulations of Hydrogenated Compounds and Their Fluorinated Analogues at $T=298.15 \mathrm{~K}^{a}$

\begin{tabular}{|c|c|c|c|c|}
\hline \multirow[b]{2}{*}{ compound } & \multicolumn{2}{|c|}{$\rho\left(\mathrm{g} \mathrm{cm}^{-3}\right)$} & \multicolumn{2}{|c|}{$\Delta H_{\text {vap }}\left(\mathrm{kcal} \mathrm{mol}^{-1}\right)$} \\
\hline & experiment & simulation & experiment & simulation \\
\hline hexanol & 0.815 & $0.812 \pm 0.003$ & $14.58 \pm 0.05$ & $13.91 \pm 0.59$ \\
\hline $1 H, 1 H$-perfluorohexanol & 1.619 & $1.611 \pm 0.004$ & $14.13 \pm 0.05$ & $13.87 \pm 0.48$ \\
\hline hexane & 0.655 & $0.648 \pm 0.004$ & $7.41 \pm 0.05$ & $7.34 \pm 0.20$ \\
\hline perfluorohexane & 1.672 & $1.670 \pm 0.005$ & $7.77 \pm 0.05$ & $7.81 \pm 0.42$ \\
\hline diglyme & 0.939 & $0.937 \pm 0.003$ & $11.47 \pm 0.05$ & $10.86 \pm 0.44$ \\
\hline perfluorodiglyme & 1.609 & $1.614 \pm 0.004$ & $8.32 \pm 0.05$ & $8.26 \pm 0.31$ \\
\hline
\end{tabular}

${ }^{a}$ Simulations use parameters from the current OPLS-AA force field ${ }^{35,36,41-44}$ as well as those derived in this work. Experimental values of $\Delta H_{\text {vap }}$ from the literature are given for hexanol $\left(\mathrm{CH}_{3}-\left(\mathrm{CH}_{2}\right)_{5}-\mathrm{OH}\right){ }^{58} 1 \mathrm{H}, 1 \mathrm{H}$-perfluorohexanol $\left(\mathrm{CF}_{3}-\left(\mathrm{CF}_{2}\right)_{4}-\mathrm{CH}_{2}-\mathrm{OH}\right),{ }^{59}$ hexane $\left(\mathrm{CH}_{3}-\left(\mathrm{CH}_{2}\right)_{4}-\mathrm{CH}_{3}\right)$, perfluorohexane $\left(\mathrm{CF}_{3}-\left(\mathrm{CF}_{2}\right)_{4}-\mathrm{CF}_{3}\right){ }^{58}$ and diglyme $\left(\mathrm{CH}_{3}-\mathrm{O}-\left(\mathrm{CH}_{2}-\mathrm{CH}_{2}-\mathrm{O}\right)_{2}-\mathrm{CH}_{3}\right),{ }^{58}$ and experimental values from this work are given for perfluorodiglyme $\left(\mathrm{CF}_{3}-\mathrm{O}-\left(\mathrm{CF}_{2}-\mathrm{CF}_{2}-\mathrm{O}\right)_{2}-\mathrm{CF}_{3}\right)$. Error bars represent one standard deviation.

genated counterparts; ${ }^{58}$ values for $n$-alkanes $\left(\mathrm{CH}_{3}-\left(\mathrm{CH}_{2}\right)_{n-2}-\right.$ $\left.\mathrm{CH}_{3}\right),{ }^{58}$ perfluoroalkanes $\left(\mathrm{CF}_{3}-\left(\mathrm{CF}_{2}\right)_{n-2}-\mathrm{CF}_{3}\right),{ }^{58}$ n-alcohols $\left(\mathrm{CH}_{3}-\left(\mathrm{CH}_{2}\right)_{n-1}-\mathrm{OH}\right),{ }^{58}$ and $1 \mathrm{H}, 1 \mathrm{H}$-perfluoroalcohols $\left(\mathrm{CF}_{3}-\right.$ $\left.\left(\mathrm{CF}_{2}\right)_{n-2}-\mathrm{CH}_{2}-\mathrm{OH}\right)^{59,60}$ are also included for comparison. The PFPEs have significantly lower values of $\Delta H_{\text {vap }}$ than their hydrogenated analogues, a trend which is not evident when comparing perfluoroalkanes to alkanes or $1 H, 1 H$-perfluoroalcohols to alcohols. This observation may indicate a lower degree of cohesiveness in liquid PFPEs, which may be explained by a reduction in overall polarity compared to polyethers due to the relatively similar electronegativities of oxygen and fluorine (compared to oxygen and hydrogen). Although dielectric constants for perfluorodiglyme and perfluorotriglyme are not available in the literature, they are expected to be similar to those of perfluoroalkanes $(\sim 2)^{61}$ and thus much lower than that of triglyme (7.58). ${ }^{62}$

To test the proposed hypothesis of reduced cohesion in liquid PFPEs, liquid and gas phase MD simulations using parameters from the current OPLS-AA force field ${ }^{35,36,41-44}$ and those developed herein were performed for diglyme $\left(\mathrm{CH}_{3}-\mathrm{O}-\right.$ $\left.\left(\mathrm{CH}_{2}-\mathrm{CH}_{2}-\mathrm{O}\right)_{2}-\mathrm{CH}_{3}\right)$, hexane $\left(\mathrm{CH}_{3}-\left(\mathrm{CH}_{2}\right)_{4}-\mathrm{CH}_{3}\right)$, hexanol $\left(\mathrm{CH}_{3}-\left(\mathrm{CH}_{2}\right)_{5}-\mathrm{OH}\right)$, and their fluorinated counterparts. Predicted values of $\Delta H_{\text {vap }}$ from these simulations are shown in Table 8; again, only the PFPE demonstrates a significant reduction in $\Delta H_{\text {vap }}$ compared to its hydrogenated analogue. To explore the intermolecular interactions between neighboring molecules in these systems, the radial distribution function (RDF) between backbone atoms (excluding atoms from the same molecule) was determined from the liquid-phase simulation trajectories, which were performed at the experimental densities (see Table 8). RDFs calculated between backbone carbon atoms are shown for hydrogenated and fluorinated ethers (Figure 6A), alkanes (Figure 6B), and alcohols (Figure 6C). Examination of these results shows that, for all systems, the location of the first RDF peak (which corresponds to nearest neighbor distance) is shifted to a larger radius upon fluorination, which is expected since fluorine is larger than hydrogen. Also, the RDF indicates loss of a distinct second peak and reduced intensity (i.e., correlation) of the first peak for perfluorodiglyme (as compared to diglyme); note that both hexanol and hexane retain the second peak and exhibit an increase in first neighbor correlation upon fluorination. This observation, which supports the proposed hypothesis of reduced cohesion in liquid PFPEs, may be explained by considering the behavior of backbone oxygen atoms in PFPEs compared to polyethers. As previously mentioned, oxygen and fluorine have relatively similar electronegativities compared to

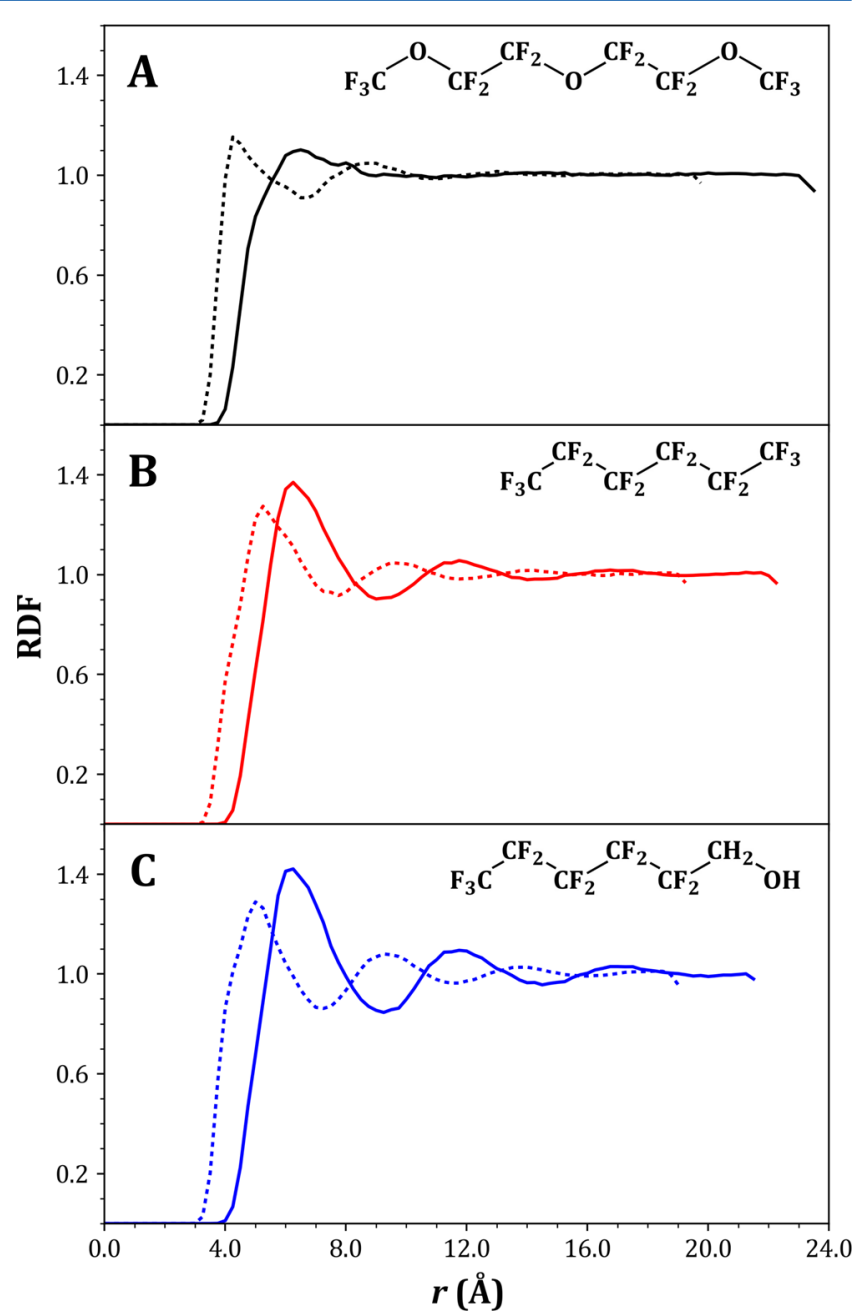

Figure 6. Radial distribution function (RDF) calculated between backbone carbon atoms of hydrogenated molecules (dotted lines) compared to their fluorinated analogues (solid lines) at $T=298.15 \mathrm{~K}$; inset diagrams show fluorinated analogues. The RDF is shown for (A) diglyme $\left(\mathrm{CH}_{3}-\mathrm{O}-\left(\mathrm{CH}_{2}-\mathrm{CH}_{2}-\mathrm{O}\right)_{2}-\mathrm{CH}_{3}\right)$ and perfluorodiglyme $\left(\mathrm{CF}_{3}-\mathrm{O}-\left(\mathrm{CF}_{2}-\mathrm{CF}_{2}-\mathrm{O}\right)_{2}-\mathrm{CF}_{3}\right)$, (B) hexane $\left(\mathrm{CH}_{3}-\left(\mathrm{CH}_{2}\right)_{4}-\mathrm{CH}_{3}\right)$ and perfluorohexane $\left(\mathrm{CF}_{3}-\left(\mathrm{CF}_{2}\right)_{4}-\mathrm{CF}_{3}\right)$, and $(\mathrm{C})$ hexanol $\left(\mathrm{CH}_{3}-\right.$ $\left.\left(\mathrm{CH}_{2}\right)_{5}-\mathrm{OH}\right)$ and $1 \mathrm{H}, 1 \mathrm{H}$-perfluorohexanol $\left(\mathrm{CF}_{3}-\left(\mathrm{CF}_{2}\right)_{4}-\mathrm{CH}_{2}-\right.$ $\mathrm{OH})$. Note the RDF only includes atoms in separate molecules.

oxygen and hydrogen, so PFPEs likely have reduced overall polarity and weaker interactions with neighboring molecules when compared to polyethers. Due to their high electro- 


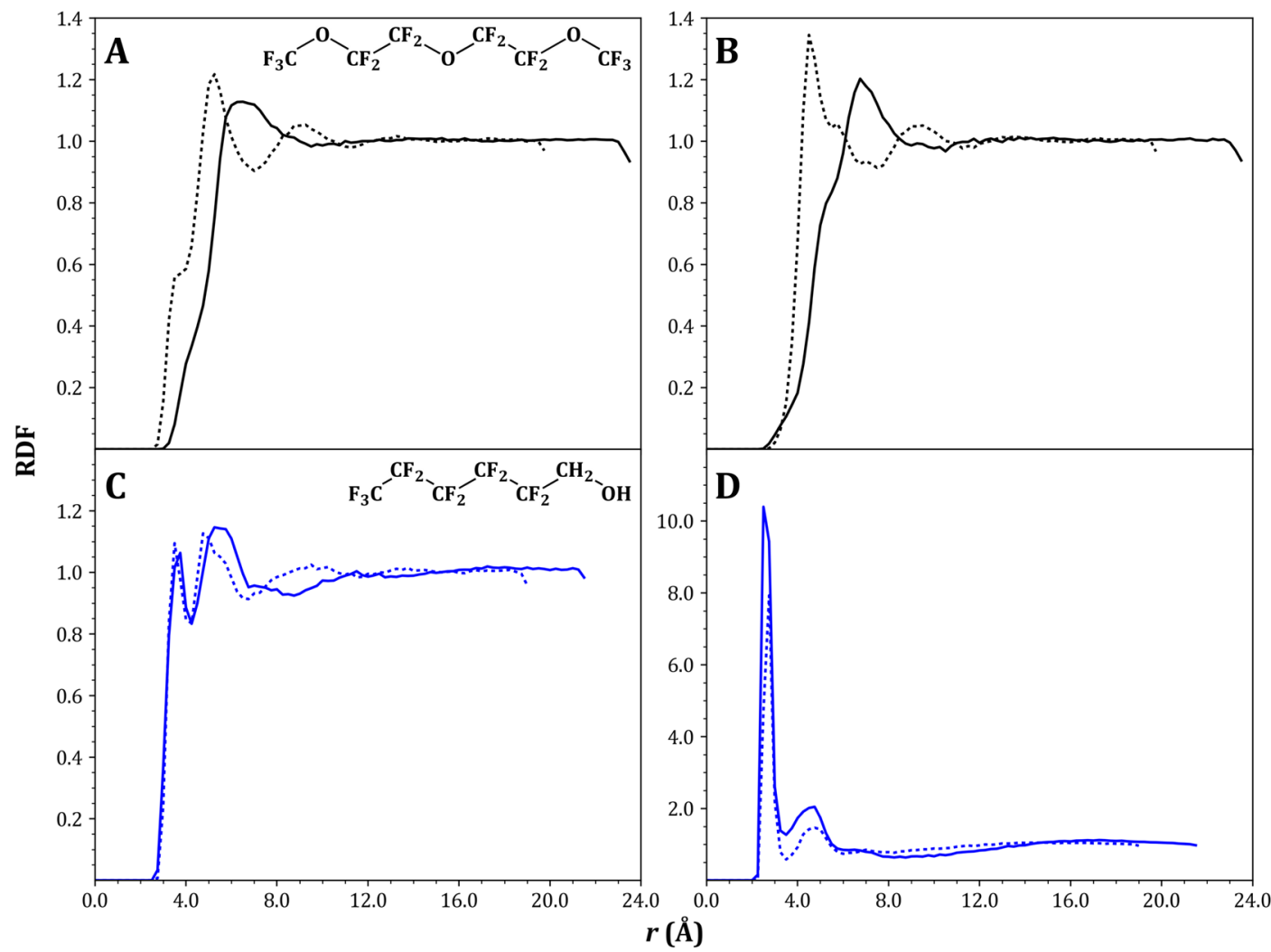

Figure 7. Radial distribution function (RDF) calculated between (A and C) backbone carbon and oxygen atoms and (B and D) backbone oxygen atoms of hydrogenated molecules (dotted lines) compared to their fluorinated analogues (solid lines) at $T=298.15 \mathrm{~K}$; inset diagrams $(\mathrm{A}$ and $\mathrm{C}$ ) show fluorinated analogues. The RDF is shown for $(\mathrm{A}$ and $\mathrm{B})$ diglyme $\left(\mathrm{CH}_{3}-\mathrm{O}-\left(\mathrm{CH}_{2}-\mathrm{CH}_{2}-\mathrm{O}\right)_{2}-\mathrm{CH}_{3}\right)$ and perfluorodiglyme $\left(\mathrm{CF}_{3}-\mathrm{O}-\left(\mathrm{CF}_{2}-\right.\right.$ $\left.\left.\mathrm{CF}_{2}-\mathrm{O}\right)_{2}-\mathrm{CF}_{3}\right)$ and $(\mathrm{C}$ and $\mathrm{D})$ hexanol $\left(\mathrm{CH}_{3}-\left(\mathrm{CH}_{2}\right)_{5}-\mathrm{OH}\right)$ and $1 \mathrm{H}, 1 \mathrm{H}$-perfluorohexanol $\left(\mathrm{CF}_{3}-\left(\mathrm{CF}_{2}\right)_{4}-\mathrm{CH}_{2}-\mathrm{OH}\right)$. Note the RDF only includes atoms in separate molecules.

negativity and large size (as compared to hydrogen), fluorine atoms are expected to significantly reduce or even block access to oxygen atoms adjacent to $\mathrm{CF}_{n}$ groups. This hypothesis is supported by results from a prior simulation study showing that perfluorotelomer alcohols (i.e., $1 \mathrm{H}, 1 \mathrm{H}$-perfluoroalcohols $\left(\mathrm{CF}_{3}-\left(\mathrm{CF}_{2}\right)_{n-2}-\mathrm{CH}_{2}-\mathrm{OH}\right)$ and $1 \mathrm{H}, 1 \mathrm{H}, 2 \mathrm{H}, 2 \mathrm{H}$-perfluoroalcohols $\left.\left(\mathrm{CF}_{3}-\left(\mathrm{CF}_{2}\right)_{n-3}-\left(\mathrm{CH}_{2}\right)_{2}-\mathrm{OH}\right)\right)$ have values of $\Delta H_{\text {vap }}$ comparable to those of $n$-alcohols, whereas perfluoroalcohols $\left(\mathrm{CF}_{3}-\left(\mathrm{CF}_{2}\right)_{n-1}-\mathrm{OH}\right)$ have significantly lower values. ${ }^{39}$ The relative decrease in $\Delta H_{\text {vap }}$ observed for perfluoroalcohols $(\sim 2.3$ $\left.\mathrm{kcal} \mathrm{mol}^{-1}\right)$ is somewhat less pronounced than that for PFPEs $\left(\sim 4.2 \mathrm{kcal} \mathrm{mol}^{-1}\right)$, possibly because perfluoroalcohols have only one hydroxyl oxygen atom adjacent to $\mathrm{CF}_{n}$ compared to several backbone oxygen atoms in PFPEs. To test this hypothesis of weakened interactions between oxygen atoms adjacent to $\mathrm{CF}_{n}$ and neighboring molecules, the RDF was calculated between backbone carbon and oxygen atoms (Figure $7 \mathrm{~A}$ ) and between backbone oxygen atoms (Figure 7B) for diglyme and perfluorodiglyme. In both cases, loss of a distinct second peak and reduced correlation in the first peak is once again observed for perfluorodiglyme compared to diglyme. For comparison, the RDF was also calculated between carbon and oxygen atoms (Figure 7C) and between oxygen atoms (Figure 7D) for hexanol and $1 H, 1 H$-perfluorohexanol. In both cases, the RDFs calculated between carbon and oxygen atoms exhibit a double-peak structure; the first subpeak corresponds to the first neighbor correlation between the oxygen atoms and carbon atoms bonded to hydroxyl groups and the second subpeak corresponds to correlation between oxygen atoms and the remaining backbone carbon atoms. Examination of this second subpeak shows that hexanol again exhibits an increase in first neighbor correlation upon fluorination. The RDFs calculated between oxygen atoms both in $1 \mathrm{H}, 1 \mathrm{H}$-perfluorohexanol and in hexanol are quite similar; in this case, oxygen atoms are part of hydroxyl (i.e., $\mathrm{OH}$ ) groups and interact through hydrogen bonding, as shown by the sharp and intense first peak of the RDF. ${ }^{63,64}$ These results further support the proposed hypothesis of reduced cohesion in liquid PFPEs, as well as the assertion that this phenomenon is due to a reduction in localized associations between backbone oxygen atoms and neighboring molecules.

\section{CONCLUSIONS}

In this work, experiments, $a b$ initio quantum mechanical calculations, and molecular dynamics simulations were combined to derive and validate an all-atom force field for PFPEs that is compatible with the current OPLS-AA force field. ${ }^{35}$ Experiments were performed to determine vapor pressures and liquid densities as a function of temperature for two small PFPEs, perfluorodiglyme and perfluorotriglyme; molar enthalpies of vaporization were calculated from the experimental vapor pressures. Bonded parameters were determined using minimum energy molecular structures and rotational energy profiles obtained from $a b$ initio calculations at the RHF/6-31G* level. Nonbonded parameters were derived by fitting to molecular dynamics simulations using the unitedatom force field for PFPEs developed by Li et al.,, ${ }^{2,3}$ which was shown to accurately reproduce experimental densities for 
several small perfluoroethers. Overall, molecular dynamics simulations of PFPEs using the new all-atom force field demonstrate excellent agreement with $a b$ initio calculations and experimental measurements, and additionally show significant improvement over equivalent simulations using the current OPLS-AA parameters for related molecules (e.g., hydrogenated ethers $^{35,42}$ and perfluoroalkanes ${ }^{36,43,44}$ ). It was further shown, via both experiment and simulation, that PFPEs demonstrate significantly lower enthalpies of vaporization than polyethers, which was not observed when comparing alkanes to perfluoroalkanes or alcohols to $1 \mathrm{H}, 1 \mathrm{H}$-perfluoroalcohols. For these systems, simulation trajectories were used to calculate the radial distribution function between backbone carbon and/or oxygen atoms as a function of molecular species; the results indicate a reduced degree of cohesiveness in liquid PFPEs compared to polyethers, which is largely due to a decrease in localized associations between backbone oxygen atoms and neighboring molecules.

\section{ASSOCIATED CONTENT}

\section{S Supporting Information}

The Supporting Information is available free of charge on the ACS Publications website at DOI: 10.1021/acs.jpcb.7b00891.

Tabulated force field parameters, tabulated experimental densities, and energy profiles and molecular structures from $a b$ initio calculations for all dihedrals specific to PFPEs (PDF)

\section{AUTHOR INFORMATION}

\section{Corresponding Author}

*E-mail: c.mccabe@vanderbilt.edu. Phone: (615) 322-6853.

\section{ORCID}

Jana E. Black: 0000-0002-6368-8477

Eduardo J. M. Filipe: 0000-0003-4440-7710

Clare McCabe: 0000-0002-8552-9135

\section{Notes}

The authors declare no competing financial interest.

Force field parameters and usage semantics, following conventions detailed previously, ${ }^{65}$ are available online at http://dx.doi.org/10.5281/zenodo.583310.

\section{ACKNOWLEDGMENTS}

This work is supported by the National Science Foundation (NSF) through grants ACI-1047828 and ACI-1535150. Computational resources were provided by the National Energy Research Scientific Computing Center (NERSC), which is supported by the Office of Science of the U.S. Department of Energy under contract DE-AC02-05CH11231. J.E.B. also acknowledges support from the U.S. Department of Education for Graduate Assistance in Areas of National Need (GAANN) Fellowship under grant P200A090323. E.J.M.F., P.M., and L.F.G.M. acknowledge support from Fundação para a Ciência e a Tecnologia through grants UID/QUI/0100/2013, SFRH/BPD/81748/2011, and PEst-OE/QUI/UI0619/2011.

\section{REFERENCES}

(1) Walther, H. C.; Bell, G. A.; Howell, J. L. Perfluoroalkylpolyethers. In Synthetics, Mineral Oils, and Bio-Based Lubricants: Chemistry and Technology, 2nd ed.; Rudnick, L. R., Ed.; CRC Press, Taylor \& Francis Group, LLC: Boca Raton, FL, 2013; pp 185-202.

(2) Li, H. C.; McCabe, C.; Cui, S. T.; Cummings, P. T.; Cochran, H. D. Development of a Force Field for Molecular Simulation of the
Phase Equilibria of Perfluoromethylpropyl Ether. Mol. Phys. 2002, 100, 265-272.

(3) Li, H. C.; McCabe, C.; Cui, S. T.; Cummings, P. T.; Cochran, H. D. On the Development of a General Force Field for the Molecular Simulation of Perfluoroethers. Mol. Phys. 2003, 101, 2157-2169.

(4) Jones, W. R.; Bierschenk, T. R.; Juhlke, T. J.; Kawa, H.; Lagow, R. J. Preparation of New Perfluoro Ether Fluids Exhibiting Excellent Thermal-Oxidative Stabilities. Ind. Eng. Chem. Res. 1988, 27, 14971502.

(5) Krytox Performance Lubricants for the Aerospace and Aviation Industries. https://www.chemours.com/Lubricants/en_US/ industries/Aerospace_Industry.html (accessed June 6, 2016).

(6) Applications and Benefits of Perfluoroether (PFPE) Lubricants; HUSK-ITT Corporation (HUSKEY Specialty Lubricants): Norco, CA, 2005.

(7) Fowzy, M. A. PFPE, A Unique Lubricant for a Unique Application; Castrol Industrial North America, Specialty Products Division: Downers Grove, IL, 1998.

(8) UniFlor PFPE LUBRICANTS, the Most Complete Line of PFPE Lubricants for Extreme Environments.; Nye Lubricants, Inc. (Nye ${ }^{\circledR}$ Synthetic Lubricants): Fairhaven, MA, 2014.

(9) Lubricants for the Food Processing and Pharmaceutical Industry. http://www.bechem.de/en/lubricants/lubricants-for-the-foodprocessing-and-pharmaceutical-industry.html (accessed June 6, 2016).

(10) Food Safe Grease \& Oils; IKV Tribology Ltd: Raglan, Monmouthshire, U.K.

(11) Fomblin ${ }^{\circledR}$ PFPE Lubes for Vacuum Applications; Solvay Specialty Polymers: Alpharetta, GA, 2015.

(12) Fomblin Z. Derivatives, Product Data Sheet; Solvay Solexis, Inc.: Alpharetta, GA, 2002.

(13) Berman, D.; Krim, J. Surface Science, MEMS and NEMS: Progress and Opportunities for Surface Science Research Performed on, or by, Microdevices. Prog. Surf. Sci. 2013, 88, 171-211.

(14) Maboudian, R. Surface Processes in MEMS Technology. Surf. Sci. Rep. 1998, 30, 207-269.

(15) Guo, Q.; Izumisawa, S.; Phillips, D. M.; Jhon, M. S. Surface Morphology and Molecular Conformation for Ultrathin Lubricant Films with Functional End Groups. J. Appl. Phys. 2003, 93, 87078709.

(16) Chen, H.; Guo, Q.; Jhon, M. S. Effects of Molecular Structure on the Conformation and Dynamics of Perfluoropolyether Nanofilms. IEEE Trans. Magn. 2007, 43, 2247-2249.

(17) Fukuda, M.; Zhang, H.; Ishiguro, T.; Fukuzawa, K.; Itoh, S. Adhesion Properties of Nanometer-Thick Perfluoropolyether Films Confined Between Solid Surfaces: A Coarse-Grained Molecular Dynamics Study. Tribol. Lett. 2013, 51, 479-487.

(18) Fukuda, M.; Zhang, H.; Ishiguro, T.; Fukuzawa, K.; Itoh, S. Structure-Based Coarse-Graining for Inhomogeneous Liquid Polymer Systems. J. Chem. Phys. 2013, 139, 054901.

(19) Kobayashi, T.; Zhang, H.; Fukuzawa, K.; Itoh, S. In CoarseGrained Molecular Dynamics Simulation of Nanometer-Thick Polar Lubricant Films Sheared Between Solid Surfaces with Random Roughness, 2015 IEEE Magnetics Conference (INTERMAG), May 11-15, 2015; pp 1 .

(20) Zhang, H.; Fukuda, M.; Washizu, H.; Kinjo, T.; Yoshida, H.; Fukuzawa, K.; Itoh, S. Shear Thinning Behavior of Nanometer-Thick Perfluoropolyether Films Confined Between Corrugated Solid Surfaces: A Coarse-Grained Molecular Dynamics Study. Tribol. Int. 2016, 93, 163-171.

(21) DEMNUM GREASE, Product Information; Daikin North America LLC.: Waller, TX, 2010.

(22) Jiang, B.; Keffer, D. J.; Edwards, B. J. Estimation and Analysis of the Rheological Properties of a Perfluoropolyether through Molecular Dynamics Simulation. J. Fluorine Chem. 2006, 127, 787-795.

(23) Tani, H.; Kubota, M.; Kanda, M.; Terao, M.; Tagawa, N. Electric-Field-Assisted Dip Coating Process of Ultrathin PFPE Lubricant Film for Magnetic Disks. IEEE Trans. Magn. 2009, 45, 3636-3639. 
(24) Tani, H.; Sakamoto, K.; Tagawa, N. Conformation of Ultrathin PFPE Lubricants with Different Structure on Magnetic Disks - Direct Observation and MD Simulation. IEEE Trans. Magn. 2009, 45, 50505054.

(25) Tani, H.; Shimizu, T.; Kobayashi, N.; Taniike, Y.; Mori, K.; Tagawa, N. Study of Molecular Conformation of PFPE Lubricants With Multidentate Functional Groups on Magnetic Disk Surface by Experiments and Molecular Dynamics Simulations. IEEE Trans. Magn. 2010, 46, 1420-1423.

(26) Tani, H.; Iwasaki, K.; Nakayama, M.; Maruyama, Y.; Ota, I.; Tagawa, N. In Lubricant Pickup on Ultra-Thin PFPE Lubricants with Different Backbone Structure, APMRC, 2010 Digest, Nov 10-12, 2010; pp 1-2.

(27) Dai, L.; Satyanarayana, N.; Sinha, S. K.; Tan, V. B. C. Analysis of PFPE Lubricating Film in NEMS Application via Molecular Dynamics Simulation. Tribol. Int. 2013, 60, 53-57.

(28) Dai, L.; Sorkin, V.; Sha, Z. D.; Pei, Q. X.; Branicio, P. S.; Zhang, Y. W. Molecular Dynamics Simulations on the Frictional Behavior of a Perfluoropolyether Film Sandwiched between Diamond-like-Carbon Coatings. Langmuir 2014, 30, 1573-1579.

(29) Kamei, D.; Zhou, H.; Suzuki, K.; Konno, K.; Takami, S.; Kubo, M.; Miyamoto, A. Computational Chemistry Study on the Dynamics of Lubricant Molecules Under Shear Conditions. Tribol. Int. 2003, 36, 297-303.

(30) da Rocha, S. R. P.; Johnston, K. P.; Rossky, P. J. SurfactantModified $\mathrm{CO}_{2}$-Water Interface: A Molecular View. J. Phys. Chem. B 2002, 106, 13250-13261.

(31) Senapati, S.; Berkowitz, M. L. Molecular Dynamics Simulation Studies of Polyether and Perfluoropolyether Surfactant Based Reverse Micelles in Supercritical Carbon Dioxide. J. Phys. Chem. B 2003, 107, 12906-12916.

(32) Lu, L.; Berkowitz, M. L. The Effect of the Rigidity of Perfluoropolyether Surfactant on Its Behavior at the Water/Supercritical Carbon Dioxide Interface. J. Phys. Chem. B 2005, 109, 2172521731.

(33) Lowrey, A. H.; George, C.; D’Antanio, P.; Karle, J. Estimation of the Torsional Potential for Perfluorodi-Methyl Ether from ElectronDiffraction Data. J. Mol. Struct. 1980, 63, 243-248.

(34) Jones, P. M.; Tang, H.; Yan, X.; Stirniman, M.; Li, L.; Hsia, Y.-T. Torsional Energy Barriers in Dimethyl Ether and Perfluoro-Dimethyl Ether: Electronic Structure Contributions. Tribol. Lett. 2011, 44, 177185.

(35) Jorgensen, W. L.; Maxwell, D. S.; Tirado-Rives, J. Development and Testing of the OPLS All-Atom Force Field on Conformational Energetics and Properties of Organic Liquids. J. Am. Chem. Soc. 1996, 118, 11225-11236.

(36) Watkins, E. K.; Jorgensen, W. L. Perfluoroalkanes: Conformational Analysis and Liquid-State Properties from ab Initio and Monte Carlo Calculations. J. Phys. Chem. A 2001, 105, 4118-4125.

(37) Morgado, P.; Black, J.; Lewis, J. B.; Iacovella, C. R.; McCabe, C.; Martins, L. F. G.; Filipe, E. J. M. Viscosity of Liquid Systems Involving Hydrogenated and Fluorinated Substances: Liquid Mixtures of (Hexane + Perfluorohexane). Fluid Phase Equilib. 2013, 358, 161-165.

(38) Chitra, R.; Smith, P. E. A Comparison of the Properties of 2,2,2Trifluoroethanol and 2,2,2-Trifluoroethanol/Water Mixtures Using Different Force Fields. J. Chem. Phys. 2001, 115, 5521-5530.

(39) Zygmunt, W.; Potoff, J. J. The Effect of Fluorination on the Physical Properties and the Free Energies of Hydration of 1-Alcohols. Fluid Phase Equilib. 2016, 407, 314-321.

(40) Morgado, P.; Das, G.; McCabe, C.; Filipe, E. J. M. Vapor Pressure of Perfluoroalkylalkanes: The Role of the Dipole. J. Phys. Chem. B 2015, 119, 1623-1632.

(41) GROMACS. http://www.gromacs.org/ (accessed June 6, 2016).

(42) Weiner, S. J.; Kollman, P. A.; Nguyen, D. T.; Case, D. A. An All Atom Force Field for Simulations of Proteins and Nucleic Acids. J. Comput. Chem. 1986, 7, 230-252.
(43) Gough, C. A.; Debolt, S. E.; Kollman, P. A. Derivation of Fluorine and Hydrogen Atom Parameters Using Liquid Simulations. J. Comput. Chem. 1992, 13, 963-970.

(44) Cornell, W. D.; Cieplak, P.; Bayly, C. I.; Gould, I. R.; Merz, K. M.; Ferguson, D. M.; Spellmeyer, D. C.; Fox, T.; Caldwell, J. W.; Kollman, P. A. A Second Generation Force Field for the Simulation of Proteins, Nucleic Acids, and Organic Molecules. J. Am. Chem. Soc. 1995, 117, 5179-5197.

(45) Frisch, M. J.; Trucks, G. W.; Schlegel, H. B.; Scuseria, G. E.; Robb, M. A.; Cheeseman, J. R.; Scalmani, G.; Barone, V.; Mennucci, B.; Petersson, G. A.; et al. Gaussian 09; Gaussian, Inc.: Wallingford, CT, 2009.

(46) Plimpton, S. Fast Parallel Algorithms for Short-Range Molecular Dynamics. J. Comput. Phys. 1995, 117, 1-19.

(47) Gray, J.; Moore, K. T.; Naylor, B. A. In OpenMDAO: An Open Source Framework for Multidisciplinary Analysis and Optimization, AIAA/ISSMO Multidisciplinary Analysis and Optimization Conference, Fort Worth, TX, 2010.

(48) Jorgensen, W. L.; Tirado-Rives, J. The OPLS [Optimized Potentials for Liquid Simulations] Potential Functions for Proteins, Energy Minimizations for Crystals of Cyclic Peptides and Crambin. J. Am. Chem. Soc. 1988, 110, 1657-1666.

(49) Salvi-Narkhede, M.; Adcock, J. L.; Gakh, A.; Van Hook, W. A. Vapor Pressures, Liquid Molar Volumes, Vapor Non-Ideality, and Critical Properties of $\mathrm{CF}_{3} \mathrm{OCF}_{2} \mathrm{CF}_{2} \mathrm{CF}_{3}, c-\mathrm{CF}_{2} \mathrm{CF}_{2} \mathrm{CF}_{2} \mathrm{CF}_{2} \mathrm{O}$, $\mathrm{CF}_{3} \mathrm{OCF}_{2} \mathrm{OCF}_{3}$, and $\mathrm{CF}_{3} \mathrm{OCF}_{2} \mathrm{CF}_{2} \mathrm{H}$. J. Chem. Thermodyn. 1993, 25, 643-647.

(50) Nosé, S. A Unified Formulation of the Constant Temperature Molecular Dynamics Methods. J. Chem. Phys. 1984, 81, 511-519.

(51) Hoover, W. G. Canonical Dynamics: Equilibrium Phase-Space Distributions. Phys. Rev. A: At., Mol., Opt. Phys. 1985, 31, 1695-1697.

(52) Hunter, J. D. Matplotlib: A 2D Graphics Environment. Comput. Sci. Eng. 2007, 9, 90-95.

(53) Kasai, P. H.; Myers, R. J. Microwave Spectrum, Structure, and Internal Rotation of Dimethyl Ether. J. Chem. Phys. 1959, 30, 10961097.

(54) Blukis, U.; Kasai, P. H.; Myers, R. J. Microwave Spectra and Structure of Dimethyl Ether. J. Chem. Phys. 1963, 38, 2753-2760.

(55) Humphrey, W.; Dalke, A.; Schulten, K. VMD: Visual Molecular Dynamics. J. Mol. Graphics 1996, 14, 33-38.

(56) Wang, J.; Hou, T. Application of Molecular Dynamics Simulations in Molecular Property Prediction. 1. Density and Heat of Vaporization. J. Chem. Theory Comput. 2011, 7, 2151-2165.

(57) Cui, S. T.; Siepmann, J. I.; Cochran, H. D.; Cummings, P. T. Intermolecular Potentials and Vapor-Liquid Phase Equilibria of Perfluorinated Alkanes. Fluid Phase Equilib. 1998, 146, 51-61.

(58) Acree, W.; Chickos, J. S. Phase Transition Enthalpy Measurements of Organic and Organometallic Compounds. Sublimation, Vaporizationand Fusion Enthalpies From 1880 to 2010. J. Phys. Chem. Ref. Data 2010, 39, 043101.

(59) Silva, G. M. C.; Morgado, P.; Haley, J. D.; Montoya, V. M. T.; McCabe, C.; Martins, L. F. G.; Filipe, E. J. M. Vapor Pressure and Liquid Density of Fluorinated Alcohols: Experimental, Simulation and GC-SAFT-VR Predictions. Fluid Phase Equilib. 2016, 425, 297-304.

(60) Costa, J. C. S.; Fulem, M.; Schröder, B.; Coutinho, J. A. P.; Monte, M. J. S.; Santos, L. M. N. B. F. Evidence of an Odd-Even Effect on the Thermodynamic Parameters of Odd Fluorotelomer Alcohols. J. Chem. Thermodyn. 2012, 54, 171-178.

(61) Boswell, P. G.; Lugert, E. C.; Rábai, J.; Amin, E. A.; Bühlmann, P. Coordinative Properties of Highly Fluorinated Solvents with Amino and Ether Groups. J. Am. Chem. Soc. 2005, 127, 16976-16984.

(62) Rivas, M.; Iglesias, T. P.; Pereira, S. M.; Banerji, N. On the Permittivity and Density Measurements of Binary Systems of $\{$ Triglyme $+(n$-Nonane or $n$-Dodecane $)\}$ at Various Temperatures. J. Chem. Thermodyn. 2005, 37, 61-71.

(63) Duarte, P.; Silva, M.; Rodrigues, D.; Morgado, P.; Martins, L. F. G.; Filipe, E. J. M. Liquid Mixtures Involving Hydrogenated and Fluorinated Chains: $(p, \rho, T, x)$ Surface of (Ethanol $+2,2,2-$ 
Trifluoroethanol), Experimental and Simulation. J. Phys. Chem. B 2013, 117, 9709-9717.

(64) Morgado, P.; Garcia, A. R.; Ilharco, L. M.; Marcos, J.; Anastácio, M.; Martins, L. F. G.; Filipe, E. J. M. Liquid Mixtures Involving Hydrogenated and Fluorinated Alcohols: Thermodynamics, Spectroscopy, and Simulation. J. Phys. Chem. B 2016, 120, 10091-10105.

(65) Iacovella, C. R.; Sallai, J.; Klein, C.; Ma, T. In Idea Paper: Development of a Software Framework for Formalizing Forcefield AtomTyping for Molecular Simulation, 4th Workshop on Sustainable Software for Science: Practice and Experiences (WSSSPE4), 2016. 